\title{
NUMERICAL MODELLING AND OPTIMISATION OF NATURAL CONVECTION HEAT LOSS SUPPRESSION IN A SOLAR CAVITY RECEIVER WITH PLATE FINS
}

\author{
L. C. Ngo ${ }^{1}$, T. Bello-Ochende ${ }^{2}$ and J. P. Meyer ${ }^{1}$ \\ 1 Department of Mechanical and Aeronautical Engineering, University of Pretoria, Pretoria, Private Bag X20, Hatfield 0028, \\ South Africa \\ 2 Department of Mechanical Engineering, University of Cape Town, Private Bag X3, Rondebosch 7701, Cape Town, South \\ Africa
}

\begin{abstract}
This study details the numerical modeling and optimization of natural convection heat suppression in a solar cavity receiver with plate fins. The use of plate fins attached to the inner aperture surface is presented as a possible low cost means of suppressing natural convection heat loss in a cavity receiver. In the first part of the study a three-dimensional numerical model that captures the heat transfer and flow processes in the cavity receiver is analyzed, and the possibilities of optimization were then established. The model is laminar in the range of Raleigh number, inclination angle, plate height and thickness considered. In the second part of the study, the geometric parameters considered were optimized using optimization program with search algorithm. The results indicate that significant reduction on the natural convection heat loss can be achieved from cavity receivers by using plate fins, and an optimal plate fins configuration exit for minimal natural convection heat loss for a given range of Raleigh number. Reduction of up to a maximum of $20 \%$ at $0^{\circ}$ receiver inclination was observed. The results obtained provide a novel approach for improving design of cavity receiver for optimal performance.
\end{abstract}

Keywords: Parabolic dish; Cavity receiver; Natural convection; plate fin; Raleigh number. 


\section{Nomenclature}

$\begin{array}{ll}\text { Alphabetical Symbols } \\ D & \text { Cavity diameter, } \mathrm{m} \\ d & \text { Aperture diameter, } \mathrm{m} \\ C_{p} & \text { Specific heat capacity, } \mathrm{J} /(\mathrm{kg} . \mathrm{K}) \\ h_{c} & \text { Convective heat transfer coefficient, } \mathrm{W} /\left(\mathrm{m}^{2} \mathrm{~K}\right) \\ H & \text { Plate fin height, } \mathrm{m} \\ H / W & \text { Dimensionless plate fin height } \\ \mathrm{K} & \text { Kelvin } \\ \mathrm{J} & \text { Joules } \\ k & \text { Thermal conductivity, W/( } \mathrm{mK}) \\ \mathrm{kg} & \text { Kilogram } \\ \mathrm{m} & \text { Metre } \\ N & \text { Number of fins } \\ N u & \text { Nusselt number } \\ P & \text { Pressure, Pa } \\ P r & \text { Prandtl number } \\ P a & \text { Pascal } \\ Q & \text { Heat loss, W } \\ R a & \text { Raleigh number } \\ \mathrm{S} & \text { Fin space, m } \\ t & \text { Plate fin thickness, } \mathrm{m} \\ t / W & \text { Dimensionless plate fin thickness } \\ T & \text { Temperature, } \mathrm{K} \\ T_{s} & \text { Surface temperature, } \mathrm{K} \\ \mathbf{V} & \text { Velocity vector, } \mathrm{m} / \mathrm{s} \\ \mathrm{W} & \text { Watt } \\ \mathbf{X} & \text { Mass force vector, } \mathrm{N} / \mathrm{kg} \\ & \end{array}$

Greek symbols

$\varphi$

$\rho$

Receiver inclination angle, degree

Density of air, $\mathrm{kg} / \mathrm{m}^{3}$

Dynamic viscosity, $\mathrm{kg} /(\mathrm{m} . \mathrm{s})$

$\varepsilon$

Fin effectiveness

Subscript

$c \quad$ convection

$s \quad$ surface

$\infty \quad$ Ambient

Abbreviation

ANU

Australia National University

CFD

Computational Fluid Dynamics

$\mathrm{CPC}$

Compound parabolic concentrator 


\section{INTRODUCTION}

The use of concentrating solar thermal technology has great potential for generating power. The parabolic dish-receiver assembly is one such promising system among several others. It normally consists of a reflector in the form of a parabolic dish with a downward facing receiver at the focus of the dish. These systems are continuously subjected to changes in environmental conditions such as wind, solar insolation, and ambient temperature. These environmental variations coupled with changes in receiver inclination angle affect the overall receiver performance leading to energy loss. A cavity receiver is preferred in such a system to maximize the absorption of the concentrated flux. The total energy loss of solar receivers which include conduction through the receiver insulation, convection and radiation through the aperture opening to the ambient environment plays a dominant role in the light-heat conversion. Heat loss through radiation heat is dependent on the temperature, emissivity/absorptivity and the shape factors of the receiver walls, while conduction heat loss is dependent on the receiver wall temperature and the material of the insulation used. Natural convection through the receiver aperture contributes a significant fraction of the energy loss and hence it is essential to effectively minimise it in order to improve the system efficiency.

Research of flow and heat transfer for cavity receivers can greatly help to estimate the thermal performance and optimise the design of the receivers [1-3]. With cavity receivers radiation and conduction can readily be determined analytically. However, this is not the case for natural convection. The complexity of geometry, temperature and velocity fields in and around the receiver makes it difficult to use existing analytical models for predicting convective heat loss. Therefore, many significant investigations have been conducted on natural convection heat transfer in open cavities. For instance, Le Quere et al. [4] investigated heat loss characteristics of two different sized cubical cavities. They considered variations in receiver operating temperature and angle, in their study. They found convection heat loss to be strongly dependent on the cavity inclination. Harris and Lenz [5] presented a study performed by Koenig and Marvin that empirically derived a correlation for convective heat loss from cylindrical cavity type receivers, including the effects of variation in operating temperature and angle. An analytical model for convective heat loss for an open cubical cavity receiver was presented by Clausing [6]. The Clausing model was developed for a central receiver operating at much higher temperatures.

Siangsukone and Lovegrove [7] presented work on modelling and simulation of the Australia National University (ANU) $400 \mathrm{~m}^{2}$ paraboloidal dish concentrator system with a direct steam generating cavity receiver and the steam line. Taumoefolau and Lovegrove [8] presented an experimental investigation based 
on an isothermal electrically heated model cavity receiver. Kumar and Reddy [9] presented a twodimensional model to estimate the approximate natural convection heat loss from the modified cavity receiver of a fuzzy focal solar dish concentrator. Both insulation conditions and no insulation conditions are used for estimation of heat loss. The analysis of the receiver carried out was based on the assumption of the uniform and maximum solar flux distribution in the central plane of the receiver. Kumar and Reddy [10] performed a comparative study to predict the natural convection heat loss from the cavity, modified cavity and semi-cavity receivers. Reddy and Kumar [11] presented a numerical study of combined laminar natural convection and surface radiation heat transfer in a modified cavity receiver of solar parabolic dish collector. A comparison of 2-Diminsional and 3-Diminsional natural convection heat loss from a modified cavity receiver was carried out by Reddy and Kumar [12]. Prakash et al. [13] has reported experimental and numerical studies of the steady state convection heat losses occurring from a downward-facing cylindrical cavity receiver. From all the data points Nusselt number correlations as a function of receiver aperture diameter were proposed for the natural convection heat losses. Wu et al. [14] performed a three-dimensional numerical study of a heat-pipe receiver to investigate the influence of aperture size and position on natural convection heat loss taking into account the effects air property variation with temperature. Le Roux et al. [15] used the second law of thermodynamics to optimally size a modified cavity receiver under steady-state so that the parabolic dish system can have maximum net power.

Minimizing natural convection is seen as an effective method to improve the thermal efficiency of cavity receivers. Some investigations have been reported on the heat loss reduction of the cavity receiver. Kribus et al. [16] designed and demonstrated the operation of the multistage receiver under elevated temperatures, which divided the aperture into separate stages according to the irradiation distribution, to achieve high working temperature and thermal efficiency. Karni et al. [17] designed a volumetric solar receiver, nicknamed Porcupine. They demonstrated the capability of the Porcupine to endure concentrated solar flux of up to $4 \mathrm{MW} / \mathrm{m} 2$ and producing exist working fluid temperatures of up to $940{ }^{\circ} \mathrm{C}$. Reddy and Kumar [18] analyzed the heat transfer behaviour of the modified cavity receiver with cone, CPC and trumpet reflector. The results showed that the trumpet one had the better performance than other ones. Fuqing Cui et al. [19] presented a cavity receiver with quartz glass cover for the dish concentrating system. They proposed the use of a quartz glass cover to separate the receiver cavity from the ambient air and its selective coating layer to intercept the infrared radiation emitted from the inner-surface of the cavity receiver, which greatly reduced the natural convection and surface radiation heat losses. 
Heat transfer rate through the enclosures can be controlled by means of fin's configuration and literature is available [20-40]. In this study, a cavity receiver with plate fins attached to the inner aperture surface is presented as a possible low cost means of suppressing natural convection heat loss in a cavity receiver. This numerical study employs air as the working fluid, and laminar natural convection heat transfer from cavity receiver with plate fins attached to the inner aperture surface has been investigated for a range of Rayleigh number, inclination angle, fin height and thickness. Furthermore, Visualisation results, such as fluid flow and temperature contours have also been presented to gain an insight into the suppression of natural convection. In addition a numerical optimisation tool is used to select the best plate fin geometric configuration that improves the cavity receiver performance at minimum natural convection heat loss. This study presents a novel approach of suppressing natural convection heat loss in a cavity receiver and the proposed model has not been observed in literature.

\section{PHYSICAL AND MATHEMATICAL MODEL}

In this study, a three-dimensional cavity receiver is considered. Figure 1 shows the schematics of the cavity receiver and the proposed cavity with plate fins in two-dimension. Compared with the prototype cavity receiver (Figure 1a), isothermal circular plate fins were installed on the inner side of the aperture surface on the proposed receiver (Figure 1c) to suppress natural convection. Both receivers are made of copper tubing with an opening aperture diameter $(d)$ and cavity diameter $(D)$. The diameter of the receiver and its aperture are defined as $180 \mathrm{~mm}$ and $100 \mathrm{~mm}$ respectively. The copper tubes are wound spirally to get the respective shape of receiver. The outer surface of the cavity receiver is completely covered with opaque insulation. Some assumptions are made for modelling the cavity receiver: (a) there is uniform and maximum solar flux distribution in the cavity receiver (b) the surfaces of the tube are uniform and smooth for the prototype cavity receiver; (c) the plate fins are made of copper and installed on the inner side of the aperture surface between the copper tubing; (d) the temperature of air flowing through the copper tube is the same as the surface temperature of the tube. And to simply the model, the copper tubes were not considered in the simulation; (e) effects of wind are not considered (i.e. no wind case).

The idea in this paper is aimed at reducing natural convection losses in the cavity receiver thus improving its performance. The numerical study employs air as the working fluid ( $\operatorname{Pr}=0.71)$. The design variables which greatly affect the hydrodynamic performance of plate fins are the geometric parameters fin heights $\left(H_{1}, H_{2}\right.$, and $\left.H_{3}\right)$ the fin thickness $\left(t_{1}, t_{2}\right.$ and $\left.t_{3}\right)$ and the number of fins $N$ as depicted in Figure 1b. The fin height and thickness are defined as dimensionless parameters $H_{j} / W$ and $t_{j} / W$ respectively in this study (for $j=$ 
1, 2, 3). Natural convection heat loss was estimated at different Raleigh numbers, inclination angles, plate fin heights and thicknesses. The dimensionless fin heights were varied in the following range: $0.025 \leq H_{j} / W \leq 0.15$. The dimensionless thicknesses of the fins were varied in the range: $0.025 \leq t_{j} / W \leq 0.125$ and the value of $N$ was varied from zero to three, where $N=0$ indicate no fin condition. In this study the effects of the distance between two plate fins $S$ was not considered. The Raleigh Number was varied in the range: $10^{4} \leq R a \leq 10^{7}$.

For natural convection in the cavity receiver, the flow and heat transfer simulations are based on the simultaneous solution of equations describing the conservation of mass, momentum and energy of the system.

Continuity equation:

$$
\Delta \cdot(\rho \mathbf{V})=0
$$

Momentum equation:

$$
\mathbf{V} \cdot \nabla(\rho \mathbf{V})=\rho \mathbf{X}-\nabla p+\nabla^{2}(\mu \mathbf{V})
$$

Energy equation:

$$
\mathbf{V} \cdot \nabla\left(\rho c_{p} T\right)=\nabla^{2}(k T)
$$

where $\rho$ is the density of air, $\mathrm{kg} / \mathrm{m}^{3}, \mathbf{V}$ is the velocity vector of air, $\mathrm{m} / \mathrm{s}, \mathbf{X}$ is the mass force vector, N/kg, $p$ is the pressure, $\mathrm{Pa}, \mu$ is dynamic viscosity, $\mathrm{kg} /(\mathrm{m} . \mathrm{s}), c_{p}$ is the specific heat capacity at constant pressure, $\mathrm{J} /(\mathrm{kg} . \mathrm{K}), \quad k$ is thermal conductivity of air, $\mathrm{W} /(\mathrm{m} . \mathrm{K})$ and $T$ is temperature in Kelvin.

The Boussinesq approximation which has been applied in previous numerical investigations for modified cavity receivers [9-12], lead to considerable deviations at high operating temperatures, and can no longer be applicable to such receivers, because the air properties change significantly with the remarkable operating temperature increments. Polynomial relationships for density, specific heat capacity at constant pressure, 
dynamic viscosity and thermal conductivity are used to account for air property variation with temperature [41].

$$
\begin{aligned}
& \rho=7.4992 \times 10^{-9} T^{3}+1.6487 \times 10^{-5} T^{2}-1.2366 \times 10^{-2} T+3.6508 \\
& c_{p}=1.3864 \times 10^{-13} T^{4}-6.4747 \times 10^{-10} T^{3}+1.0234 \times 10^{-6} T^{2}-4.3282 \times 10^{-4} T+1.0613 \\
& \mu=1.3864 \times 10^{-15} T^{3}-1.4346 \times 10^{-11} T^{2}+5.0523 \times 10^{-8} T+4.1130 \times 10^{-6} \\
& k=1.5797 \times 10^{-17} T^{5}+9.4600 \times 10^{-14} T^{4}+2.2012 \times 10^{-10} T^{2}-2.3758 \times 10^{-7} T^{2} \\
& +1.7082 \times 10^{-4} T^{2}-7.488 \times 10^{-3}
\end{aligned}
$$

The convective heat transfer coefficient can be expressed as:

$$
h_{c}=\frac{N u k}{D}
$$

where $N u$ is the Nusselt number and $D$ is the receiver cavity diameter. The Nusselt numbers were calculated using CFD code. The convective heat loss from the modified cavity receiver is given as:

$$
Q_{c}=h_{c} A\left(T_{s}-T_{\infty}\right)
$$

The Raleigh number for all results in this study is based on the cavity receiver diameter $D$ and is defined as:

$$
R a=\frac{g \beta\left(T_{s}-T_{\infty}\right) D^{3}}{v \alpha}
$$

where $g$ is the acceleration due to gravity, $\mathrm{m} / \mathrm{s}^{2}, \quad \beta$ is the thermal expansion coefficient, $1 / \mathrm{K}, \quad v$ is the kinematic viscosity, $\mathrm{m}^{2} / \mathrm{s}$. and $\alpha$ is the thermal diffusivity, $\mathrm{m}^{2} / \mathrm{s}$.

\section{NUMERICAL PROCEDURE AND VALIDATION}

\subsection{Numerical procedure.}

A finite volume based CFD code, STAR-CCM+ 7.06 was employed in the 3D simulation of the natural convection through the aperture of the cavity receiver. Figure 2 schematically represents computational grid of the cavity receiver. In reality, the receiver is surrounded by an infinite atmosphere with a limiting 
temperature equal to ambient air temperature. In the numerical analysis, the region outside the cavity is represented by a spherical enclosure (Figure 2a). The size of the enclosure was increased until it had an insignificant effect on fluid and heat flows in the vicinity of the receiver. It was found that in STARCCM+, the diameter of the spherical enclosure should be about ten times the diameter of the receiver to achieve this.

The core volume mesh contains polyhedral cells. The cells were refined on the walls of the cavity receiver as a percentage of base cell and prism layers cells were used on the walls of the cavity receiver (Fig. 2b). This led to cells being very small in the region inside the cavity and nearby the receiver but increase in size gradually toward the spherical enclosure wall. The prism layer mesh model was used with a core volume mesh to generate orthogonal prismatic cells next to wall boundaries. This layer of cells is necessary to improve the accuracy of the flow solution [42]. An enlarged portion of the mesh is shown in Fig. $2 b$ and c.

A mesh refinement was performed on the cavity receiver, investigating the average Nusselt number on the hot inner surfaces of the cavity receiver $\left(T_{s}=800 \mathrm{~K}\right.$ and $\left.R a=10^{6}\right)$. Table 1 presents the average Nusselt numbers obtained for four different grids at two different inclination angles of the receiver $\left(\theta=0^{\circ}\right.$ and $\theta=$ $30^{\circ}$ ). The relative deviation for the Nusselt number between grid 1 and 2 was less than $1 \%$. Since the differences between the two were minor, we chose grid 2 for all the simulations presented in this work. This was considered as a good trade-off between accuracy and cost of time.

\subsubsection{Boundary Conditions.}

The model "without insulation at the aperture plane" proposed by Reddy and Kumar [12] is used in this investigation. It is assumed that the surface of the cavity receiver attains constant or almost constant surface temperature when exposed to reflected solar radiation of the parabolic concentrator and as such isothermal boundary condition was applied to the internal receiver surfaces, outer surface on the aperture plane as well as the fins. The temperature stated in the current model is stagnation temperature which corresponds to the no flow condition when no useful energy is being collected for constant insolation and the system attains peak temperature [12]. The temperature was varied from 400-1000 K. The outer spherical walls of the receiver were treated as adiabatic since it was covered with insulation to prevent heat loss. The outer domain was treated as a pressure outlet boundary condition. The wall temperature of the entire spherical enclosure was set to an ambient temperature of $300 \mathrm{~K}$. 


\subsection{Validation}

The numerical procedure was validated using the experimental work reported by Yasuaki et al. [43] as shown in table 2. The enclosed hemisphere was experimentally studied under steady state, laminar conditions. The curved portion and bottom surface were taken as cold and hot surfaces respectively. The area weighted average Nusselt numbers of hot surface of the enclosed hemisphere was obtained for different Rayleigh numbers. It was observed that the present numerical procedure is in good agreement with the experimental data with maximum deviation approximately $2.8 \%$.

\subsection{Optimization problem formulation}

The optimization problem was tailored towards finding the best plate fin geometric parameters, which give the least natural heat loss from the modified receiver cavity for different Raleigh number, and inclination angle at a given temperature. The design variables which greatly affect the hydrodynamic performance of plate fins are the plate fin heights and thicknesses as indicated in section 2. The dimensionless fin heights were varied in the following range: $0.025 \leq H_{j} / W \leq 0.15$. The dimensionless thicknesses of the fins were varied in the range: $0.025 \leq t_{j} / W \leq 0.125$. The type of optimisation considered in this study is the placement of individual plate fins to form channels. This leads to the treatment of an array of fins in which each fin is operating in an optimum manner [44].

\subsection{Optimization Approach}

The optimization problem defined in section 4.0 was solved using Optimate+ an add-on to the CFD code Star $\mathrm{CCM}+$ that adds the capability to perform automated design optimization studies using HEEDS (Hierarchical Evolutionary Engineering Design System) search algorithm called SHERPA (Systematic Hybrid Exploration that is Robust, Progressive, and Adaptive) [45]. SHERPA is an optimization package that automates the iterative design process and uses an adaptive search strategy to efficiently find optimized solutions [45]. In the SHERPA scheme, the algorithm uses the elements of multiple search techniques simultaneously (not sequentially) in a unique blended manner in attempts to take advantages of the best attributes from each methods. The optimization methods contain internal tuning parameters that are modified during the search according to the knowledge obtained from the design space. In this way, SHERPA learns about the design space and adapts in order to effectively search all types of design spaces.

The solution process for an automated design optimization study is illustrated in Figure 3. The iteration steps within the dashed box occur automatically, without human intervention. The analysis model(s) are created prior to execution of the optimization study, and the input file(s) associated with these models are modified 
by the optimization tool for each new design evaluation during the study. Aside from the analysis model(s), the key ingredient in this process is the optimization algorithm, which controls the type and direction of the search at each iteration step. Note that some optimization algorithms are very sensitive to the initial guesses of design variable values, while other methods are relatively insensitive to these values [46].

Heeds gives each design a performance rating. The value returned for the objective(s) and the degree to which a design satisfies its constraints together determine the design's performance value. So a high performance design is the one that satisfies all the constraints and has a good rating on its objective(s). All designs that satisfy the chosen constraint essentially ignore by what margin they meet those constraints. Once the constraints are satisfied, only the objectives contribute numerically to the performance evaluation. The performance value is calculated using the following equation [45]:

$\sum_{i=1}^{\text {Nobj }} \frac{S_{i} * \text { Obj }_{i}}{\text { Norm }_{i}}-\sum_{j=1}^{\text {Ncon }}$ penalty $\left(\frac{\text { ConstrntViolation }_{j}}{\text { Trget }_{j}}\right)$

where Nobj is number of objectives, $S_{i}$ is sign for the i-th objective, $O b j_{i}$ is the response value for the i-th objective, $\operatorname{Norm}_{i}$ is the normalization factor for the i-th objective, penalty ${ }_{j}$ is the penalty factor for the $\mathrm{j}$-th constraint, Ncon is the number of constraints, ConstntViolation ${ }_{j}$ is the amount by which the j-th constraint is violated, and $\operatorname{Trget}_{j}$ is target value of the $\mathrm{j}$-th constraint. For feasible design (all constraints are satisfied), the performance function is a sum of the normalised objective values. When one or more constraints are violated, the performance value of the design is reduced by a values based on the violation of the constraint (the second term in the equation) [45].

\section{RESULTS AND DISCUSSION}

\subsection{Temperature and velocity contours}

For different cavity receiver wall temperatures, the temperature and velocity distributions inside and nearby the receiver are similar and as such this paper only gives temperature and velocity contours of the cavity receiver with $T_{s}=800 \mathrm{~K}$. Temperature and velocity contours on the symmetry plane of a receiver cavity without fins and one with 3 plate fins (at $H_{j} / W=0.15$ and $t_{j} / W=0.075, j=1,2,3$ ) are depicted in Figs. 4 and 5 for $R a=10^{4}$ and $10^{7}$, respectively. From Figure $4 \mathrm{a}$ and $\mathrm{b}$, it is seen that at $R a=10^{4}$ the temperature contours exhibit a conduction dominated heat transfer regime for both the finned and unfinned cavity 
receivers. The temperature and velocity contours (Figure 4c and d) are mildly distorted since buoyance forces are not strong enough to trigger significant convection and as such the plate fins do not play a major role in the convection heat transfer.

At higher Rayleigh number, heat transfer is dominated by convection zone in the lower part of both the finned and unfinned cavities. The temperature and velocity contours are distorted by the flow and the fluid penetrates through into the cavity as seen in Figure 5(a-d). It is also noted that the thickness of the hydrodynamic boundary layer adjacent to the hot wall decreases for high $\mathrm{Ra}=10^{6}$ for most of the lower part of the cavity. From Figure $5 \mathrm{a}$ and $\mathrm{b}$ it is seen that the temperatures of the lower part of the cavity receiver walls are relatively lower, while the temperatures of the upper parts of the walls are higher. The explanation behind this is that, as air at ambient temperature is driven into the cavity receiver by the natural convective currents, the air adjacent to the receiver surface becomes hotter and lighter as it absorbs heat from the receiver surfaces and consequently flows up along the cavity wall. As a result of this, hot stagnant air appears only at the top of the cavity receiver. Eventually, the hot air leaves the cavity through the aperture and then cooled by the ambient. High temperature gradients exist across the cavity receiver aperture plane at low receiver inclination angles compared to higher angles. The effect of these large temperature gradients is that they prevent the mixing of ambient air in the receiver, thus leaving the convection zone unchanged and only decreases as the inclination increases.

In the absence of fins a clockwise-rotating vortex is formed in lower part of the cavity receiver, as shown in Figure 5a and $\mathrm{c}$. This is because of the rise of the fluid due to the buoyance effects produced by heating from the lower aperture surface. The presence of fin plates attached to the aperture surface has counteracting effects on the flow and temperature fields as shown in Figure $5 \mathrm{~b}$ and $\mathrm{d}$. The plate fins tends to create a blockage to flow movement close to the hot aperture wall, causing a weakening of the primary vortex in the lower part of the cavity thus reducing the heat transfer. The decrease in convection heat transfer in the cavity can also be attributed to decrease in velocity of fluid flowing through the small cavities created by the plate fins. This is because of the pre-heated air from the first cavity which reaches the entrance of the following cavities causing a large part of the small cavities to be occupied by hot air. The hot air prevents the cold air from ambient to enter the small cavities leading to poor heat transfer to the cavity. Hence, the driving potential to natural convection reduces in the cavity, which in turn reduces the net heat transfer.

The Nusselt numbers were evaluated for the inner aperture surface of the receiver for both cases (with and without fins) for receiver presented at $30^{\circ}$ inclination angle and $\mathrm{Ra}=10^{6}$. It was observed that there was a 
significant reduction in the Nusselt number with the insertion of fins. Under the case without fins, the Nusselt number was 20.52 compared to 12.28 , in the case of the aperture surface with fins.

\subsection{Effects of fin height}

Figure 6 show the effect of dimensionless plate fins heights $H_{j} / W$ on natural convection heat loss from the proposed cavity receiver. Natural convection heat loss is plotted against plate fin height at a given Ra and temperature for different inclination angles. As seen from Figure 6 for any receiver inclination angle $\theta$, increasing fin heights decrease the natural convection heat loss and a reduction of $19.6 \%$ is observed at all inclination angles. The decrease in natural convection is close to linear for all inclination angles. The decrease in convection heat transfer loss in the proposed cavity with plate fins is attributed to decrease in velocity of the fluid flowing through the cavities created by the plate fins as discussed in section 4.1. Increasing fin height increases the resistance of the convection cell movement between the plate fins thus further decreasing the heat transfer rate. The results show that longer plate fins causes higher natural convection heat loss suppression compared to shorter plate fins. The conclusion is that the natural convection heat loss from the proposed cavity receiver was reduced compared to the case without fins and this reduction can be enhanced by increasing fin height.

\subsection{Effect of plate fin thickness}

The dependence of the natural convection heat loss on dimensionless fin thickness $t_{j} / W$ in the proposed cavity receiver is shown in Figure 7. Natural convection heat loss is plotted against dimensionless plate fin thickness at a given $R a$ and temperature for different inclination angles.

As seen from Figure 7, at lower inclination angles ( 0 and 30 degrees) it is clear that plate fin thickness optimally exist, which minimizes natural convection heat loss in the cavity. However, natural convection heat loss does not significantly depend much on plate fin thickness but varies greatly with inclination angle of the receiver with minimum occurring at 60 degrees. Reducing the plate fin thickness will slightly increase the natural convection heat loss while increasing the plate fin thickness reduces the natural convection heat loss until an optimum thickness is reached after which the heat loss starts to increase. The decrease in convection heat transfer in the proposed cavity receiver with plate fins is attributed to the fact that at high fin thickness, the fin spacing $(S)$ is too thin to permit the formation of convection cells between each adjacent 
two plate fins thus decreasing the transfer rate. On the other hand reducing plate fin thickness increases fin spacing thus permitting the formation of convection cell and the heat transfer rate is slightly increased.

\subsection{Effects of Raleigh Number}

Figure 8 shows the variation of natural convection heat loss with $R a$ number for the cavity receiver. Natural convection heat loss is plotted against Ra for different inclination angles. It can be observed from this figure that for any cavity receiver orientations, the natural convection heat loss generally increases with increasing Ra. This can be attributed to the increase of the buoyancy force with increasing $R a$. Increasing buoyancy force increases flow driving force and consequently causes an increase of flow intensity that leads to higher heat transfer rates. Also, increasing $R a$ enhances the mixing within the air layer that leads to higher heat transfer. It is also observed that the growth in natural convection heat loss at all inclination angles of the cavity receiver is slightly lower at low $R a$ numbers as compared to that at high $R a$ numbers. This attributed to the fact heat transfer is dominated by conduction since buoyance forces are not strong enough to trigger significant convection at low $R a$. It is seen from the figure that the introduction of fin plates suppresses natural convection significantly at high $R a$ numbers compared to low $R a$ for all inclination angles of the receiver except at 90 degrees. It is also observed that increasing the fin heights further suppresses natural convection at higher $R a$. This can be attributed to the fact that plate fins do not play a significant role at low $R a$ since heat transfer is dominated by conduction. They however play a significant role at high $R a$ at which heat transfer is dominated by convection as discussed in section 4.1. It is further observed that natural convection heat loss at different Raleigh numbers varies with inclination angle of the receiver especially at high $R a$.

\subsection{Effects of number of fins}

The dependence of the natural convection heat loss on the number of plate fins on the aperture of the cavity receiver in shown is Figure 9. Natural convection heat loss is plotted against the number of plate fins $N$ for different inclination angles and fixed dimensionless fin height and thickness. It is observed from Figure 9 that, for all inclination angles of the cavity receiver, natural convection heat loss decreases with increasing number of plate fins. This variation of natural convection heat loss with the number of fins can be attributed to decrease of the flow intensity with fins insertion. The resistance of the motion of the rotating convection cells is expected to increase with increasing number of fins and this leads to weaker flow intensity. Decreasing flow intensity reduces heat transfer rate thus reducing the natural convection heat loss. 


\subsection{Effects of inclination angle}

Figure 10 shows the effect of cavity receiver inclination angle on natural convection for the unfinned and finned aperture cases having 3 plate fins and $H_{j} / W=0.075$ and 0.125 respectively. The figure shows that natural convection heat loss is greater during the side facing position ( 0 degrees) compared to the downward facing (90 degrees). This trend was noticed for both the unfinned and finned cases at the entire range of inclination angles. This can be attributed to that fact the behavior of air in the cavity receiver is completely different at varying inclination angles of the receiver. In the downward facing position of $90^{\circ}$, the cavity is almost dominated by the stagnant zone, thus convection heat loss out of the receiver is small. When the receiver inclination angle is varied anticlockwise, the stagnant zone decreases and this increases the convective zone where most of the heat transfer mainly happens. It is also observed from the figure that the introduction of plate fins suppresses natural convection for all inclination angles. The suppression is observed to be much high at lower inclination angles as compared to higher inclination angles. The increase of fin height further suppresses natural convection for all inclination angles. With the introduction of plate fins $H / W=0.125$, a reduction in natural convection heat loss of a maximum of $20 \%$ at 0 degrees and $14 \%$ at 90 degrees was observed respectively.

\subsection{Optimization results}

In this section, the optimization SHERPA algorithm was applied to obtain the best geometric configuration of the plate fins that will optimally suppress natural convection heat loss in cavity receiver. The optimal geometric parameters have significant influence on the performance of the receiver cavity as reducing natural convection will improve the performance of the cavity receiver. For each simulation, 30 optimization numerical evaluations were conducted automatically within the constraint ranges given in section 4.0 and convergence was attained after approximately 14 hours. The results are presented in table 3 . Figure 11 shows optimized results of the cavity receiver plate fin heights at all inclination angles. The optimum results is plotted together with the effect of cavity receiver inclination angle on natural convection for the unfinned and finned aperture cases having 3 plate fins and $H_{j} / W=0.075$ and 0.125 respectively. For the range of inclination angles, Figure 11 shows that natural convection heat loss is highly dependent on fin height and decreases with increasing plate fin height until the optimum is reached. This is attributed to the decrease in natural convection heat loss as discussed in Section 4.2.

Figure 12 shows optimized results of the cavity receiver plate fins thicknesses at all inclination angles. The optimum results is plotted together with the effect of cavity receiver inclination angle on natural convection 
for the unfinned and finned aperture cases having 3 plate fins and $t_{j} / W=0.075$ and 0.125 respectively. Figure 12 show that natural convection heat loss does not significantly depend on plate fin thickness and varying $t / W$ shows insignificant change in natural convection heat loss. However, we observe from the optimization study that natural convection suppression is achieved at optimum when $t_{j} / W=0.125$. Thus, it can be concluded that plate fins geometric configuration in cavity receiver could be important for optimum performance of cavities in practical applications.

Figure 13 shows the effects of the minimized natural convection heat loss $Q_{\min }$ as function of the Raleigh number for the various receiver inclination angles. It was observed that minimized natural convection heat loss increases with the increase in Raleigh number for all receiver inclination angles. It was also observed that at lower Raleigh numbers $\left(10^{4}\right.$ and $\left.10^{5}\right)$; the variation of minimized natural convection heat loss at different inclination angles of the cavity receiver is lower as compared to that at high numbers $\left(10^{6}\right.$ and $\left.10^{7}\right)$.

Figure 14 shows that the optimal dimensionless fin height $(H / W)_{o p t}$ and dimensionless fin thickness $(t / W)_{o p t}$ a constant values of 0.15 and $0.125 \mathrm{~mm}$ respectively, for different Raleigh numbers when the cavity receiver was optimized. It is also observed that the $(H / W)_{o p t}$ and $(t / W)_{o p t}$ were constant and are insensitive to receiver inclination angles for different Raleigh numbers. These graphs (Figure 13 and 14) are significant as they quantify the optimal configuration and minimized natural convection heat losses with the applied Raleigh number.

\subsection{CONCLUSIONS}

The use of plate fins attached to the inner aperture surface was presented as a possible low cost means of suppressing natural convection heat loss in a cavity receiver. A three-dimensional numerical model for heat transfer process in the cavity receiver was presented and the effects of Rayleigh number, inclination angle, fin heights and fin thicknesses on natural convection heat loss was investigated. From the temperature contours a conduction dominated heat transfer regime for both the finned and unfinned cavities was observed for low $R a$. The temperature contours are mildly distorted since buoyance forces are not strong enough to trigger significant convection and as such the plate fins do not play a major role in the convection heat transfer. At higher $R a$, heat transfer is dominated by convection in the lower part of the cavity and the isotherms are distorted by the flow and fluid penetrates through into the cavity and as such fins play a significant role. It was also found that natural convection heat loss is dependent on the receiver, inclination angle, fins height and thickness. 
The geometric parameters examined were optimized using HEEDS search algorithm called SHERPA. The major finding is that significant reduction on the natural convection heat loss from the cavity receiver can be achieved by using the plate fins, which act as heat transfer suppressor and that optimal plate fin geometries exist for minimized natural convection heat loss. Reduction up to a maximum of $20 \%$ at $0^{\circ}$ receiver inclination was observed. The results obtained provide a novel approach for improving the design of cavity receivers for optimal performance.

\section{ACKNOWLEDGEMENT}

The authors acknowledge the support of the Department of Mechanical and Aeronautical Engineering, University of Pretoria and the National Research Foundation.

\section{REFERENCE}

[1] D.J. Reynolds, M.J. Jance, M. Behnia, Morrison GL, An Experimental and computational study of the heat lost characteristics of a trapezoidal cavity absorber, Sol. Energy 76 (2004) 229-34.

[2] R. Bertocchi, J. Karni, A. Kribus, Experimental evaluation a non-isothermal high temperature solar particle receiver, Energy 29 (2004) 687-700.

[3] R. Ben-Zvi, J. Karni, Simulation of a volumetric solar reformer, J Sol. Energy-Trans ASME 129 (2007) 197-204.

[4] P. Lequere, E. Penot, M. Mirenayat, Experimental study of heat loss through natural convection from an isothermal cubic open cavity.

[5] J.A. Harris, T.G. Lenz, Thermal performance of solar concentrator/cavity receiver systems, J Sol. Energy 34(2) (1985) 135142.

[6] A.M. Clausing, Convective losses from cavity solar receivers-comparisons between analytical predictions and experimental results, J Sol. Energy Engineering 105 (1983) 29-33.

[7] P. Siangsukone, K. Lovegrove, Modelling of a steam based paraboloidal dish concentrator using the computer source code TRNSYS, Proceedings of Solar (2002) - Australian and New Zealand Solar Energy Society Paper 1.

[8] T. Taumoefola, K. Lovegrove, An Experimental Study of Natural Convection Heat Loss from a Solar Concentrator Cavity Receiver at Varying Orientation, Proceedings of Solar ( 2002) - Australian and New Zealand Solar Energy Society Paper 1.

[9] N. Sendhil Kumar, K.S. Reddy, Numerical investigation of natural convection heat loss in modified cavity receiver for fuzzy focal solar dish concentrator, J Sol. Energy 81 (2007) 846-855.

[10] N. Sendhil Kumar, K.S. Reddy, Comparison of receivers for solar dish collector system, Energy Convers. and Management 49 (2008) 812-819.

[11] K.S. Reddy, N. Sendhil Kumar, Combined laminar natural convection and surface radiation heat transfer in a modified cavity receiver of solar parabolic dish, J Therm. Sciences 47 (2008)1647-1657.

[12] K.S. Reddy, N. Sendhil Kumar, An improved model for natural convection heat loss from modified cavity receiver of solar dish concentrator. J Sol. Energy 83 (2009) 1884-1892. 
[13] M. Prakash, S.B. Kedare, J.K. Nayak, Investigations on heat losses from a solar cavity receiver. J Sol. Energy 83 (2009) 157170.

[14] S. Wu, L. Xiao, Y. Li, Effect of aperture position and size on natural convection heat loss of a solar heat-pipe receiver. J Appl. Therm. Eng. 31 (2011) 2787-2796.

[15] W. G. Le Roux, T. Bello-Ochende, J. P. Meyer, Thermodynamic optimization of an integrated design of a small-scale solar thermal Brayton cycle. Int. J. Energy Research, 36 (2012) 1088-1104.

[16] A. Kribus, P. Doron, R. Rubin, J. Karni, R. Reuven, S. Duchan, E. Taragan, A Multistage Solar Receiver: The Route To High Temperature. Sol. Energy 67 (1999) 3-11.

[17] J. Karni, A. Kribus, R. Rubin, P. Doron , The "porcupine": A novel high-flux absorber for volumetric solar receivers, J Sol. Energy Eng-Transactions of the ASME 120 (1998) 85-95.

[18] K. S Reddy, N. Sendhil Kumar, Convection and surface radiation heat losses from modified cavity receiver of solar parabolic dish collector with two-stage concentration, J Heat and Mass Transf. 45 (2009) 363-373

[19] C. Fuqing, H. Yaling, C. Zedong, L. Yinshi, Study on combined heat loss of a dish receiver with quartz glass cover, Appl. Energy (2013)

[20] P. Oosthuizen, J.T. Paul, Free convection heat transfer in a cavity fitted with a horizontal plate on the cold wall, in: S.M. Shenkman, et al. (Eds.), Advances in Enhanced Heat Transfer, 43 (1985) 101-107.

[21] S. Shakerin, M. Bohn, R.I. Loehrke, Natural convection in an enclosure with discrete roughness elements on a vertical heated wall, Int. J. Heat Mass Transfer 31 (1988) 1423-1430.

[22] R.L. Frederick, Natural convection in an inclined square enclosure with a partition attached to its cold wall, Int. J. Heat Mass Transfer 32 (1989) 87-94.

[23] R.L. Frederick, A. Valencia, Heat transfer in a square cavity with a conducting partition on its hot wall, Int. Commun. Heat Mass Transfer 16 (1989) 347-354.

[24] A. Nag, A. Sarkar, V.M.K. Sastri, Natural convection in a differentially heated square cavity with a horizontal partition plate on the hot wall, Comput. Methods Appl. Mech. Engrg. 110 (1993) 143-156.

[25] M. Hasnaoui, P. Vasseur, E. Bilgen, Natural convection in rectangular enclosures with adiabatic fins attached on the heated wall, Warme and Stoffubertragung 27 (1992) 357-368.

[26] R. Scozia, R.L. Frederick, Natural convection in slender cavities with multiple fins attached on an active wall, Numer. Heat Transfer, Part A 20 (1991) 127-158.

[27] G.N. Facas, Natural convection in a cavity with fins attached to both vertical walls, J. Thermophys. Heat Transfer 7 (1993) $555-560$.

[28] E.K. Lakhal, M. Hasnaoui, E. Bilgen, P. Vasseur, Natural convection in inclined rectangular enclosures with perfectly conducting fins attached on the heated wall, Heat Mass Transfer 32 (1997) 365-373. 
[29] E. Bilgen, Natural convection in enclosures with partial partitions, Renewable Energy 26 (2002) 257-270.

[30] X. Shi, J.M. Khodadadi, Laminar fluid flow and heat transfer in a lid driven cavity due to a thin fin, ASME J. Heat Transfer 124 (6) (2002) 1056-1063.

[31] X. Shi, J.M. Khodadadi, Laminar natural convection heat transfer in a differentially heated square cavity due to a thin fin on the hot wall, ASME J. Heat Transfer 125 (4) (2003) 624-634.

[32] E. Bilgen, Natural convection in cavities with a thin fin on the hot wall, Int. J. Heat Mass Transfer 48 (2005) 3493-3505.

[33] V.A.F. Costa, M.S.A Oliveira, A.C.M. Sousa, Control of laminar natural convection in differentially heated square enclosures using solid inserts at the corners, Int. J. Of Heat and Mass Transf. 46 (2003) 3529-3537.

[34] E. Fontana, da Silva, V.C. Mariani, Natural convection in a partially open square cavity with internal heat source: An analysis of the opening mass flow, Int. J. Of Heat and Mass Transf. 54 (2011) 1369-1386.

[35] A.K. Sharma, A. Pradeep, K. Velusamy, Chellapandi, B. Raj, Interaction of natural convection flow in multiple open cavities formed due to horizontal fins, J. Ann. of Nuclear Energy 38 (2011) 1906-1915.

[36] T.N. Anderson, M. Duke, J.K. Carson, Suppression of natural convection heat transfer coefficients in an attic shaped enclosure, Int. Commun. Heat Mass Transfer 37 (2010) 984-986.

[37] S.A. Nada, Natural convection heat transfer in horizontal and vertical closed narrow enclosures with heated rectangular finned base plate, Int. J. Heat and Mass Transfer 50 (2007) 667-679.

[38] Y Varol, H.F. Oztop, A. Varol, Effects of thin fin on natural convection in porous triangular enclosures. Int. J. Therm. Sci. 46 (2007) 1033-1045.

[39] A. Ben-Nakhi, A.J. Chamkha, Conjugate natural convection in a square enclosure with inclined thin fin of arbitrary length. Int. J. Therm. Sci. 46 (2007) 467-478

[40] A. Ben-Nakhi, M.M. Eftekhari, D.I. Loveday, Natural convection heat transfer in a partially open square cavity with a thin fin attached to the hot wall, J. Heat Transf.-Transactions of the ASME 130 (2008)

[41] A.I. Zografos, W.A. Martin, J.E. Sunderland, Equations of properties as a function of temperature for seven fluids, J Comput. Methods in Appl. Mechanics and Eng. 61 (1987) 177-187.

[42] STAR CCM+ User Guide, Version 7.06, copy right 2012 CD-adapco

[43] Y. Shiina, K. Fujimura, T. Kunugi, N. Akino, Natural convection in a hemispherical enclosure heated from below. J of Heat and Mass Transf. 37 (1994) 1605-1617.

[44] A. Kraus, A. Aziz, J. Welty, Extended Surface heat transfer. John Wiley \& Sons, Inc.

[45] HEEDS (Hierarchical Evolutionary Engineering Design System).2011. Getting Started Manual. Red Cedar Technology, MI USA

[46] N. Chase, M. Redemacher, E. Goodman, R. Averill, R. Sidhu, A benchmark study of optimisation search algorithms, Red Cedar Technology, MI, USA 


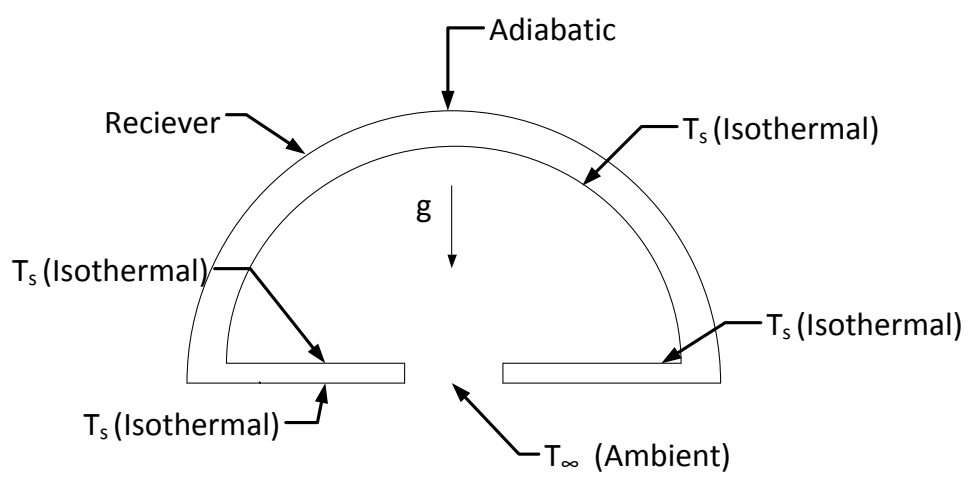

(a)

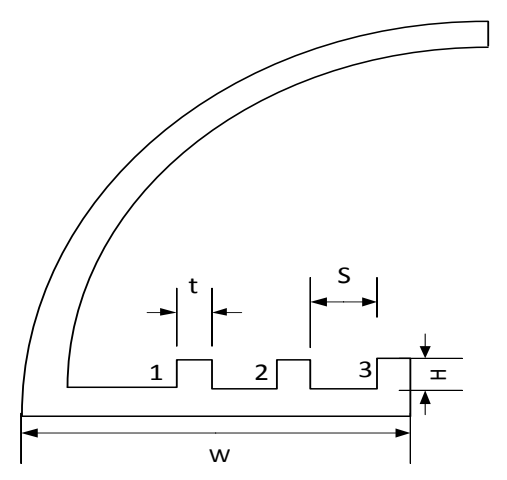

(b)

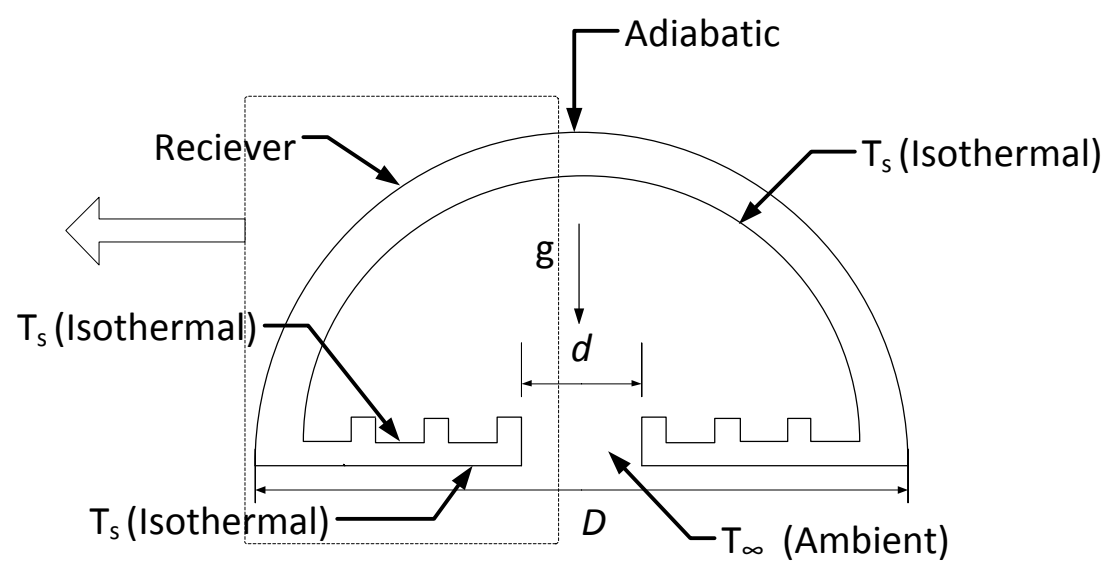

(c)

Figure 1. Schematic of modified cavity receiver with and without plate fins 

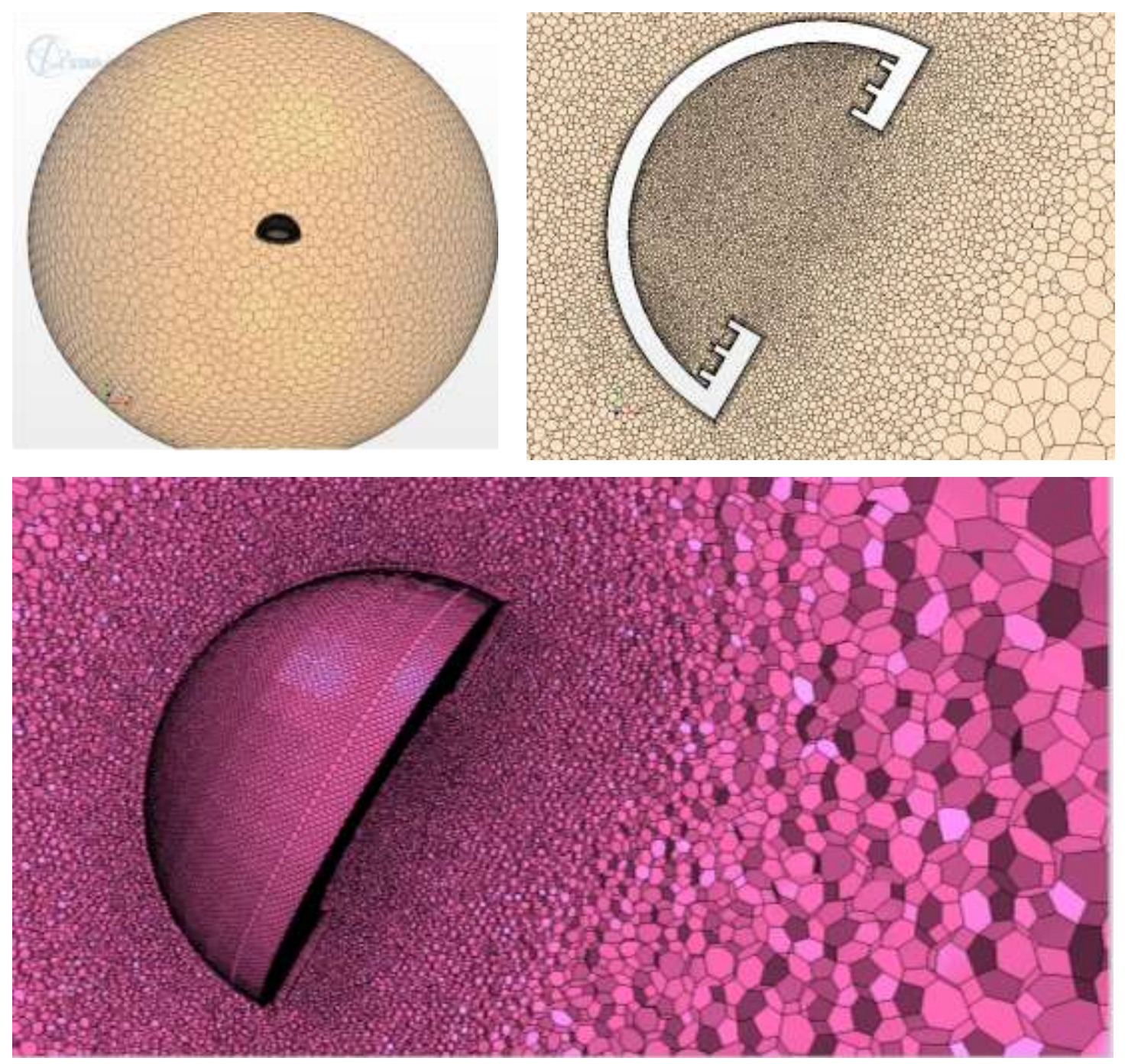

Fig. 2. Typical computational grid for the numerical analysis of the modified cavity receiver (a) 3-D including sphere (b) 2-D cross-section at $30^{\circ}$ (c) refined polyhedral cells are in and around the cavity at $30^{\circ}$ and the coarse mesh towards the sphere. 


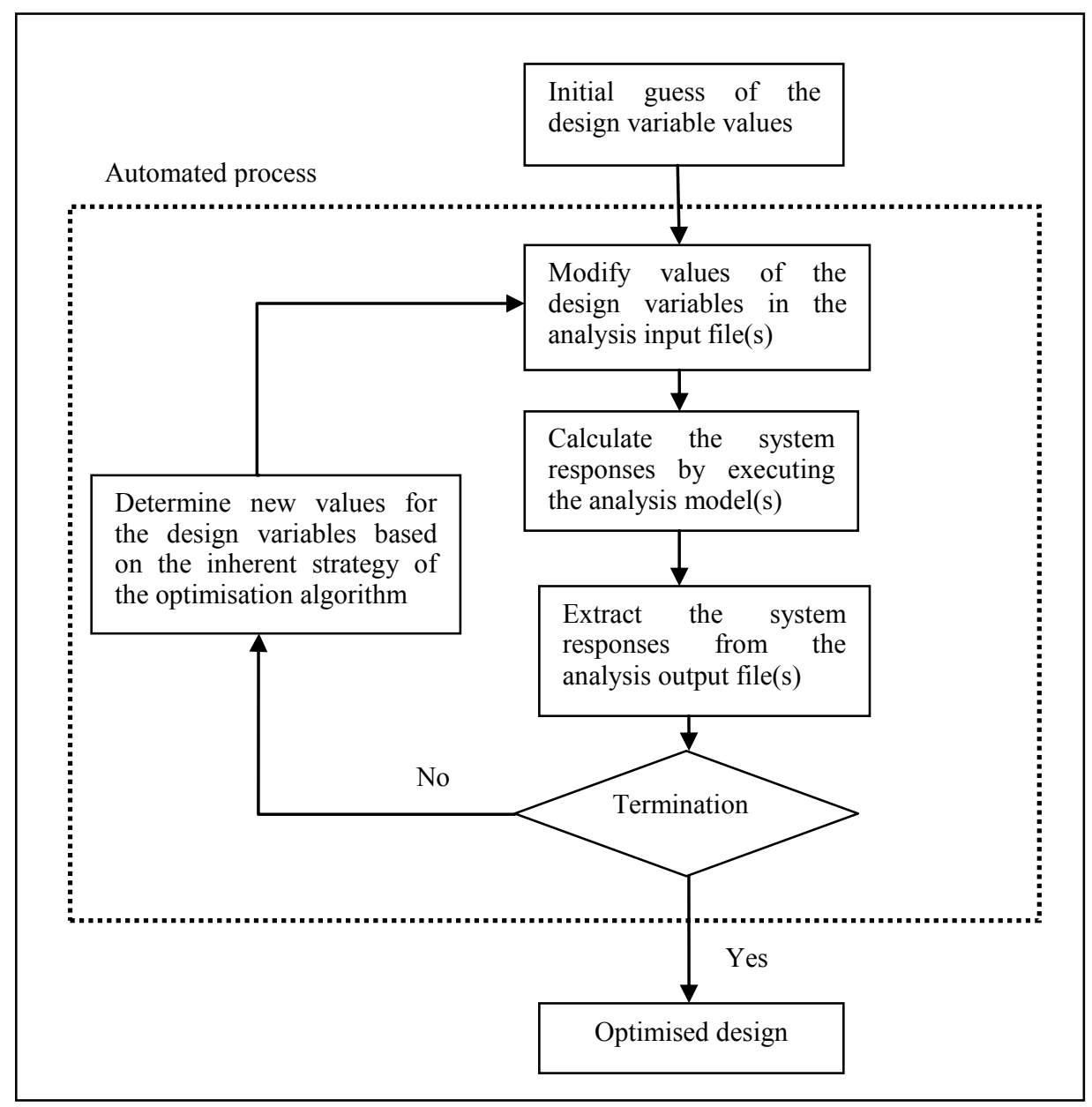

Figure 3. Automated design optimization process flowchart. 


\begin{tabular}{lllll}
\hline Cells & \multicolumn{4}{c}{ Nusselt number } \\
\cline { 2 - 5 } & $\theta=0^{\circ}$ & $\begin{array}{l}\text { Relative } \\
\text { Deviation }\end{array}$ & $\theta=30^{\circ}$ & $\begin{array}{l}\text { Relative } \\
\text { Deviation }\end{array}$ \\
\hline 801,337 & 10.1675 & & 18.2941 & \\
320,000 & 10.1529 & 0.001436 & 18.2734 & 0.001132 \\
241,336 & 10.2338 & -0.00797 & 18.2008 & 0.003973 \\
218,272 & 10.2947 & -0.00595 & 18.2096 & -0.00048 \\
\hline
\end{tabular}

Table 1 Average Nusselt numbers for different grids

\begin{tabular}{|l|l|l|l|}
\hline Rayleigh & \multicolumn{2}{|c|}{ Nusselt number } & Percentage \\
number & $\begin{array}{l}\text { Yasuaki et } \\
\text { al. }\end{array}$ & $\begin{array}{l}\text { Present } \\
\text { work }\end{array}$ & \\
\hline $1.9437 \times 10^{5}$ & 6.91 & 7.09 & -2.6 \\
\hline $2.8523 \times 10^{6}$ & 7.60 & 7.39 & 2.8 \\
\hline $4.9288 \times 10^{6}$ & 8.72 & 8.62 & 1.1 \\
\hline $7.8266 \times 10^{6}$ & 9.78 & 9.86 & -0.8 \\
\hline $1.1683 \times 10^{7}$ & 10.82 & 10.84 & -0.2 \\
\hline $2.2818 \times 10^{7}$ & 12.79 & 12.44 & 2.7 \\
\hline
\end{tabular}

Table 2 Validation of the Nusselt number by using present procedure

\begin{tabular}{|l|l|l|}
\hline \multirow{2}{*}{ Variable } & \multicolumn{2}{|c|}{ Fin Height/Thickness (m) } \\
\cline { 2 - 3 } & Initial & Optimised \\
\hline H1 & 0.005 & 0.006 \\
\hline H2 & 0.005 & 0.006 \\
\hline H3 & 0.005 & 0.006 \\
\hline t1 & 0.003 & 0.005 \\
\hline t2 & 0.003 & 0.005 \\
\hline t3 & 0.003 & 0.005 \\
\hline
\end{tabular}

Table 3. Optimisation results 


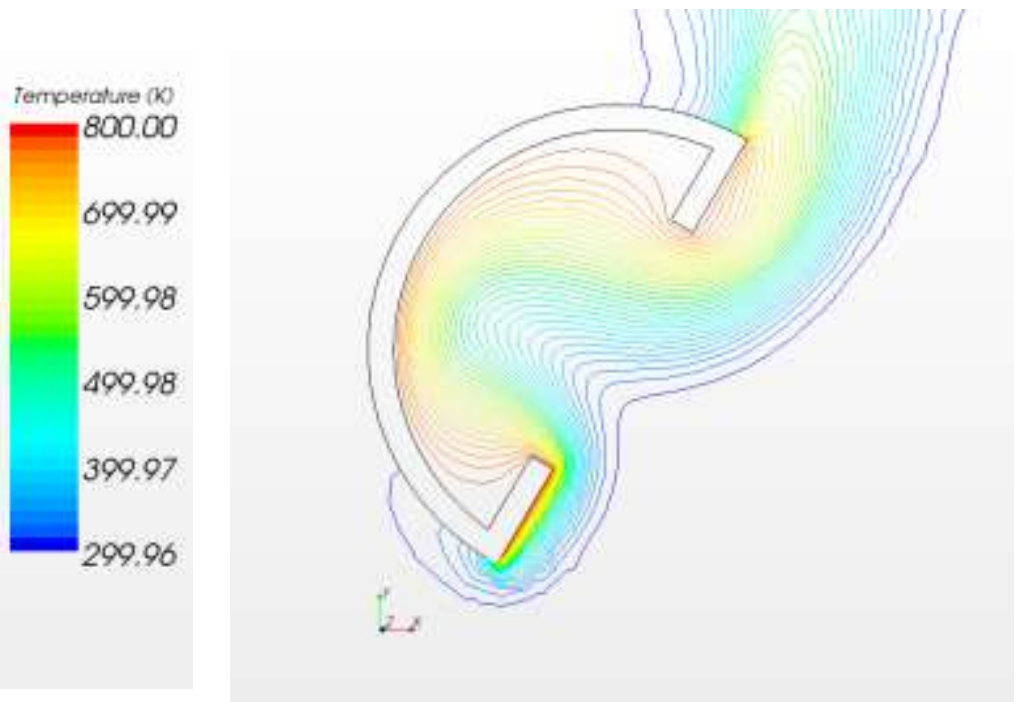

(a)

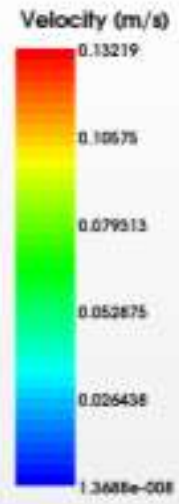

(c)

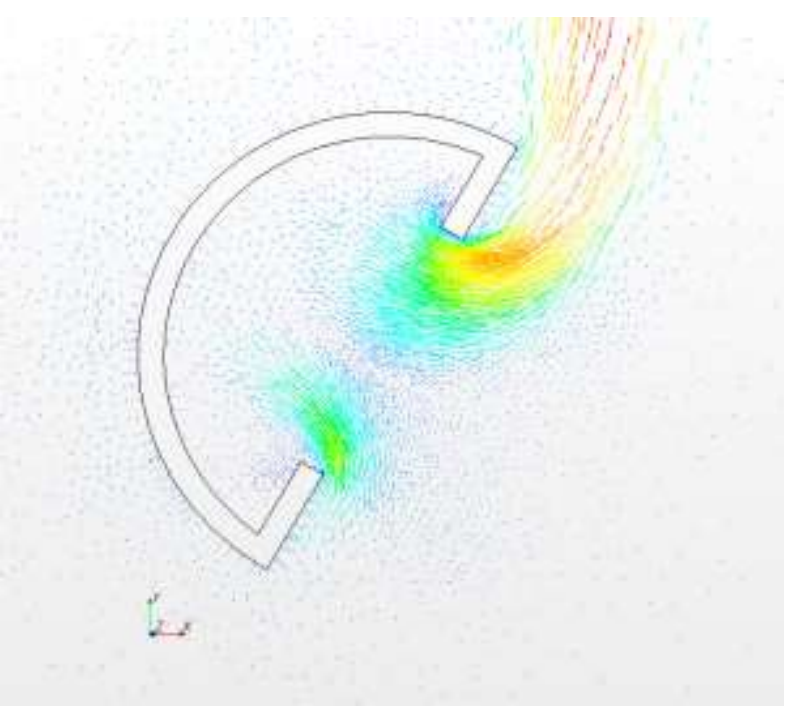

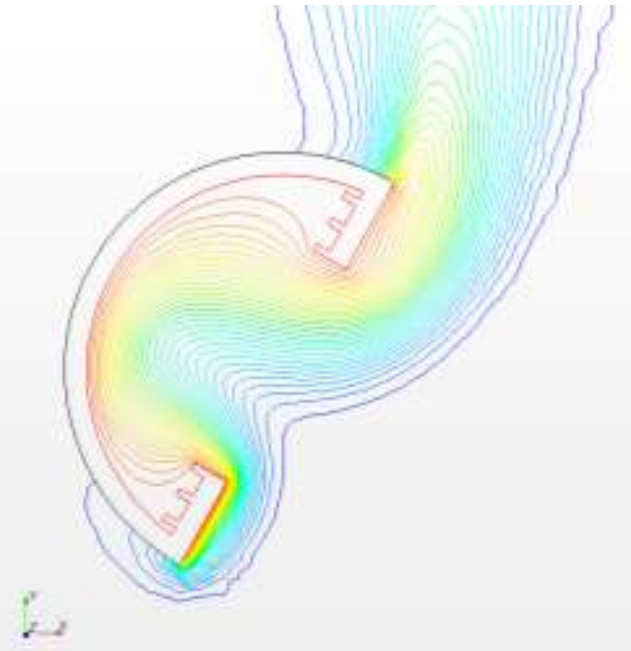

(b)

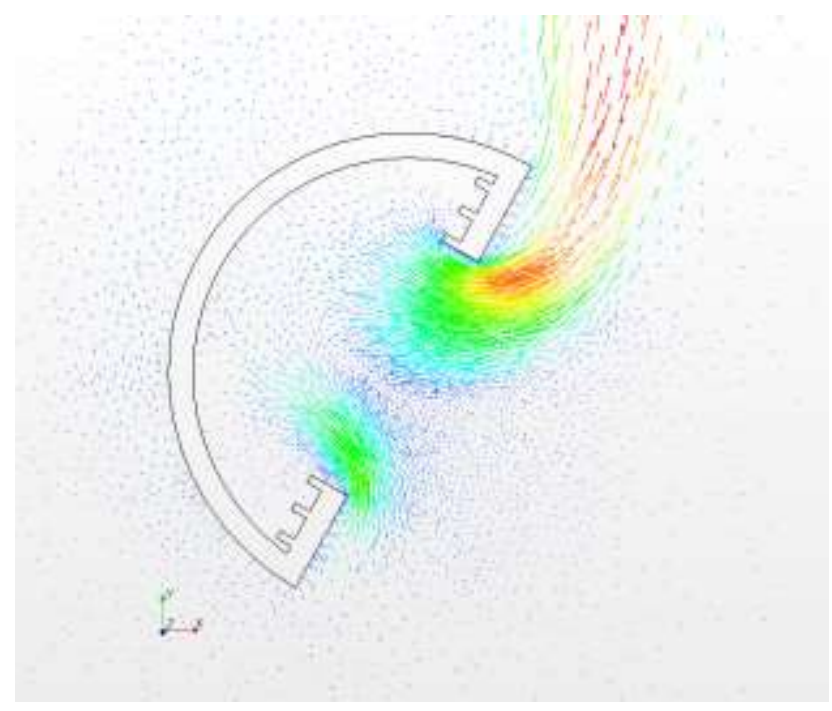

(d)

Figure 4. Temperature and velocity contours on the symmetry plane respectively, at $60^{\circ}$ cavity inclination, $R a=10^{4}, H / W=$ $0.15, t / W=0.075$ for cavity unfinned and finned cavities 


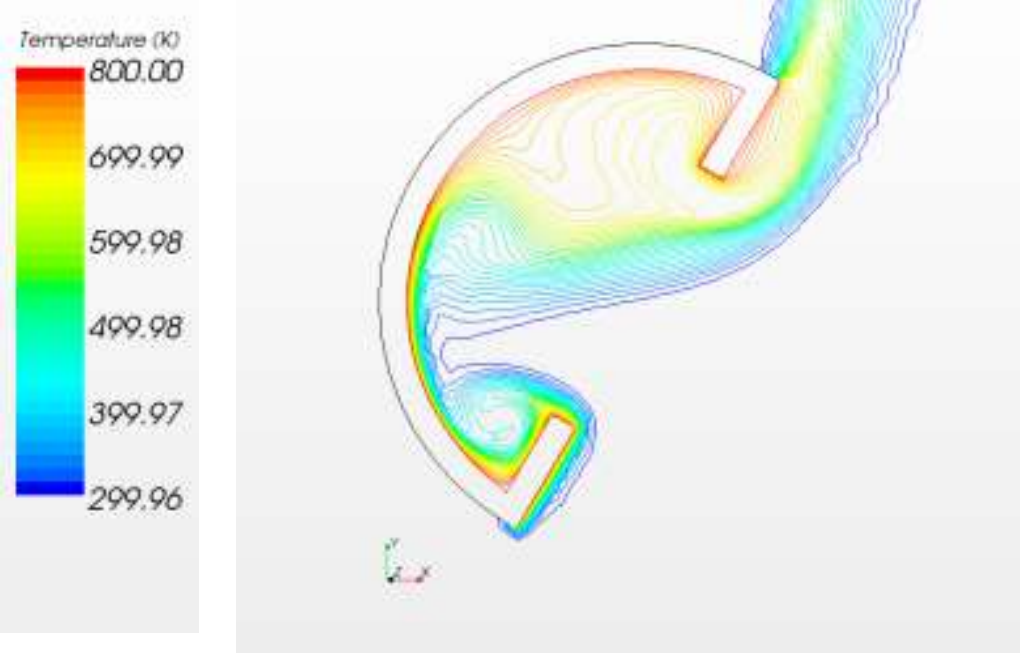

(a)

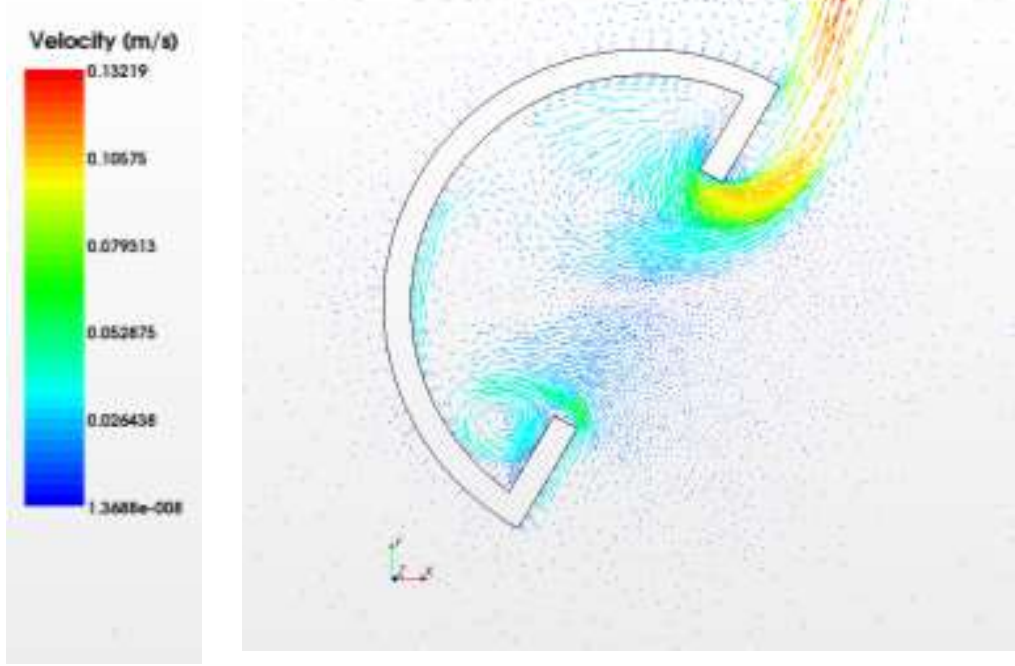

(c)

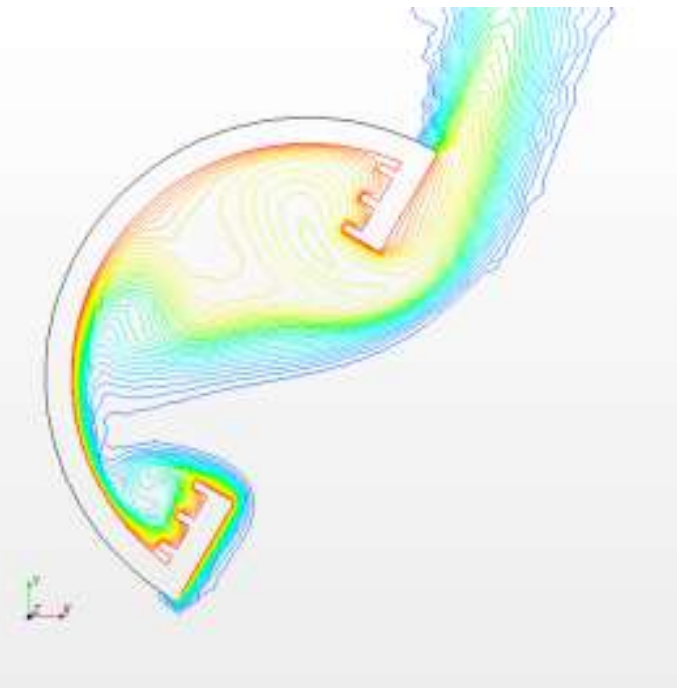

(b)

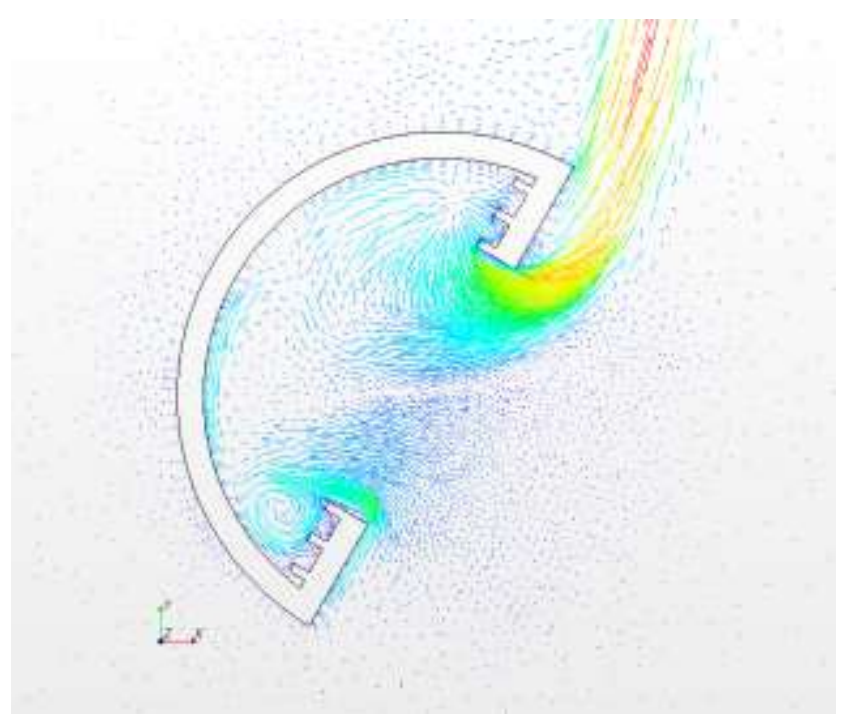

(d)

Figure 5. Temperature and velocity contours on the symmetry plane respectively, at $60^{\circ}$ cavity inclination, $\operatorname{Ra}=10^{6}, H / W=0.15$, $t / W=0.075$ for cavity unfinned and finned cavities 


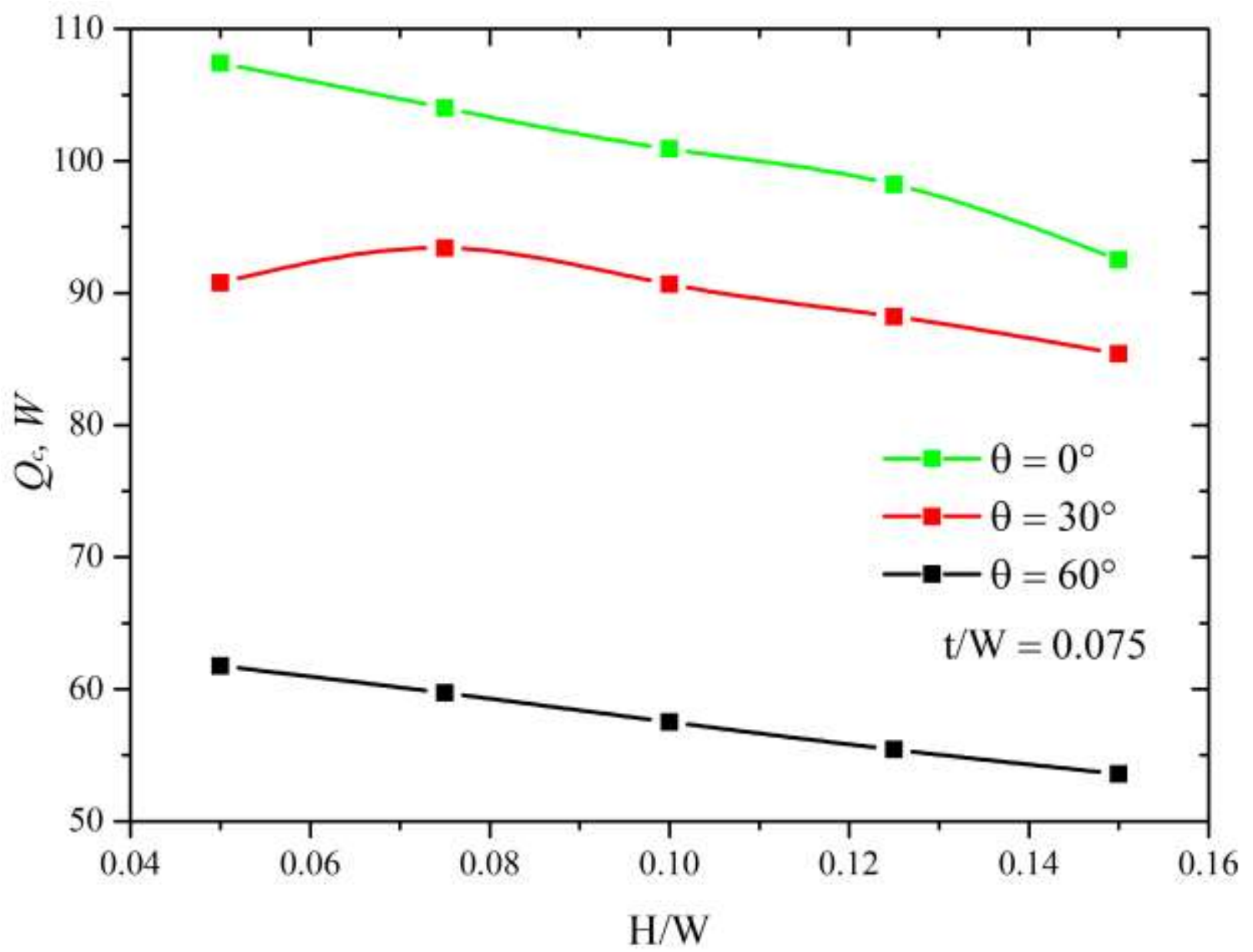

Figure 6. Effect of plate fins height on natural convection heat loss from the proposed cavity receiver, $R a=10^{6}$ 


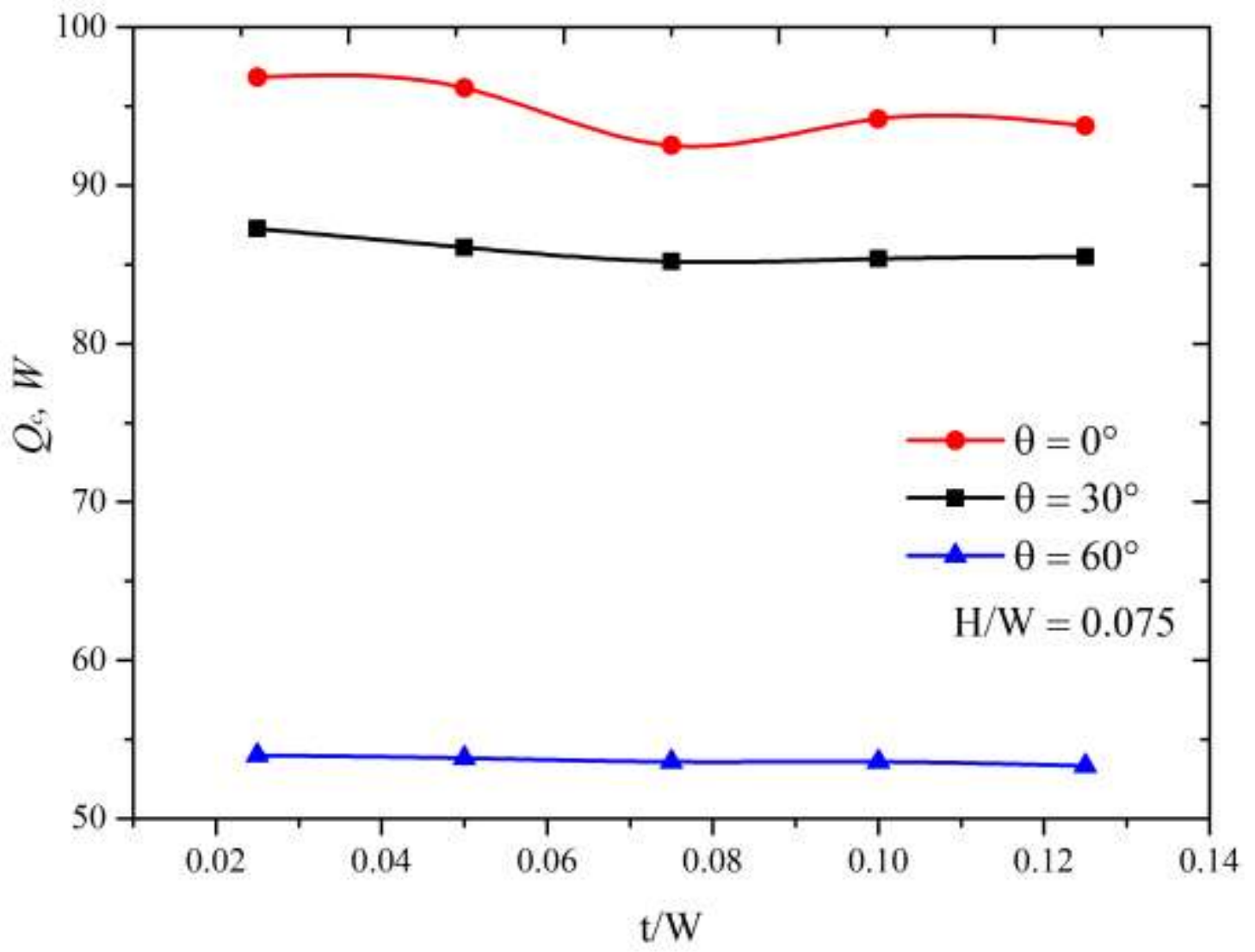

Figure 7. Effect of plate fins thickness on natural convection heat loss from the proposed modified cavity, $R a=10^{6}$ 


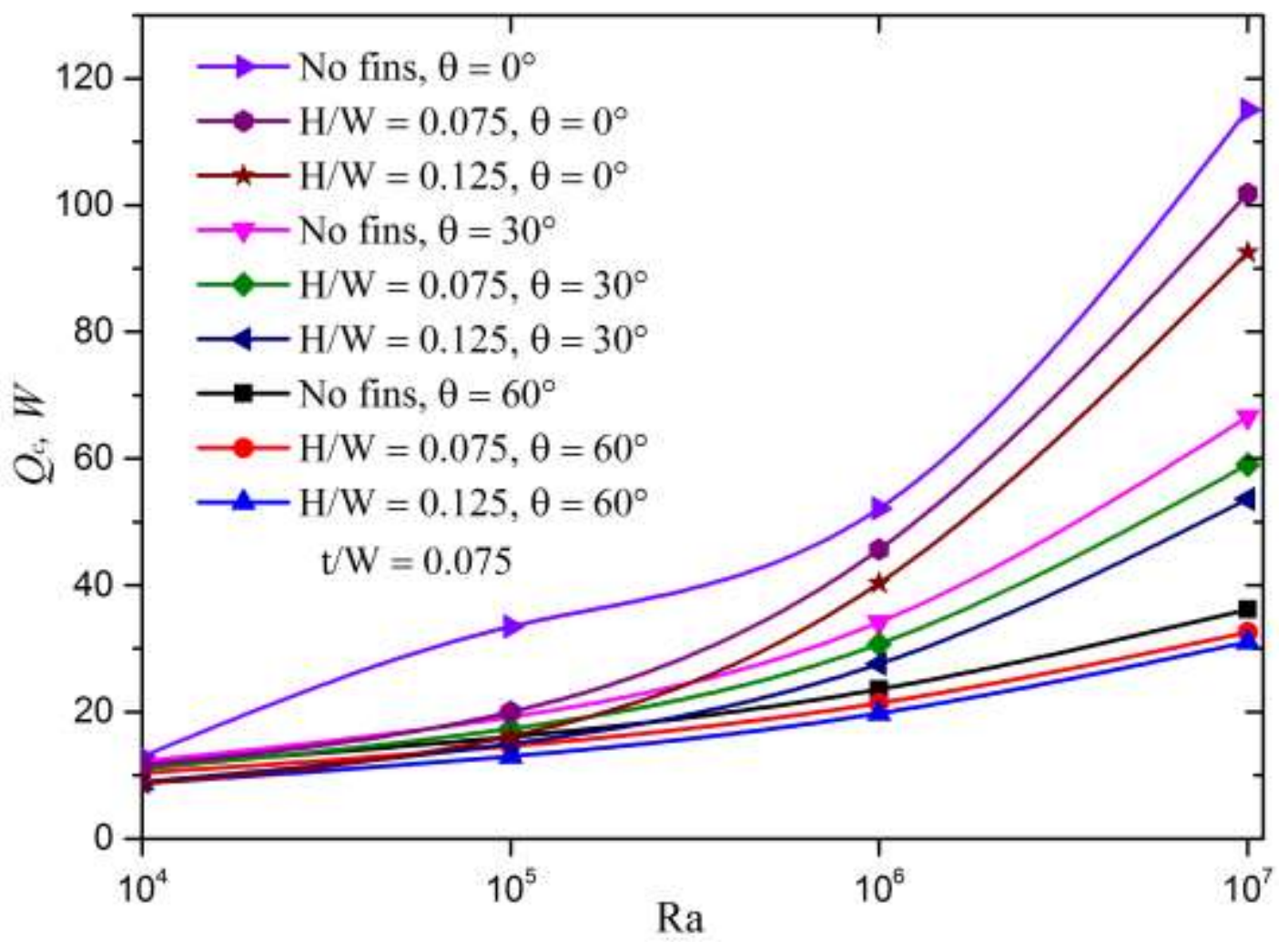

Figure 8. Effect of Raleigh number on natural convection heat loss from the proposed modified cavity. 


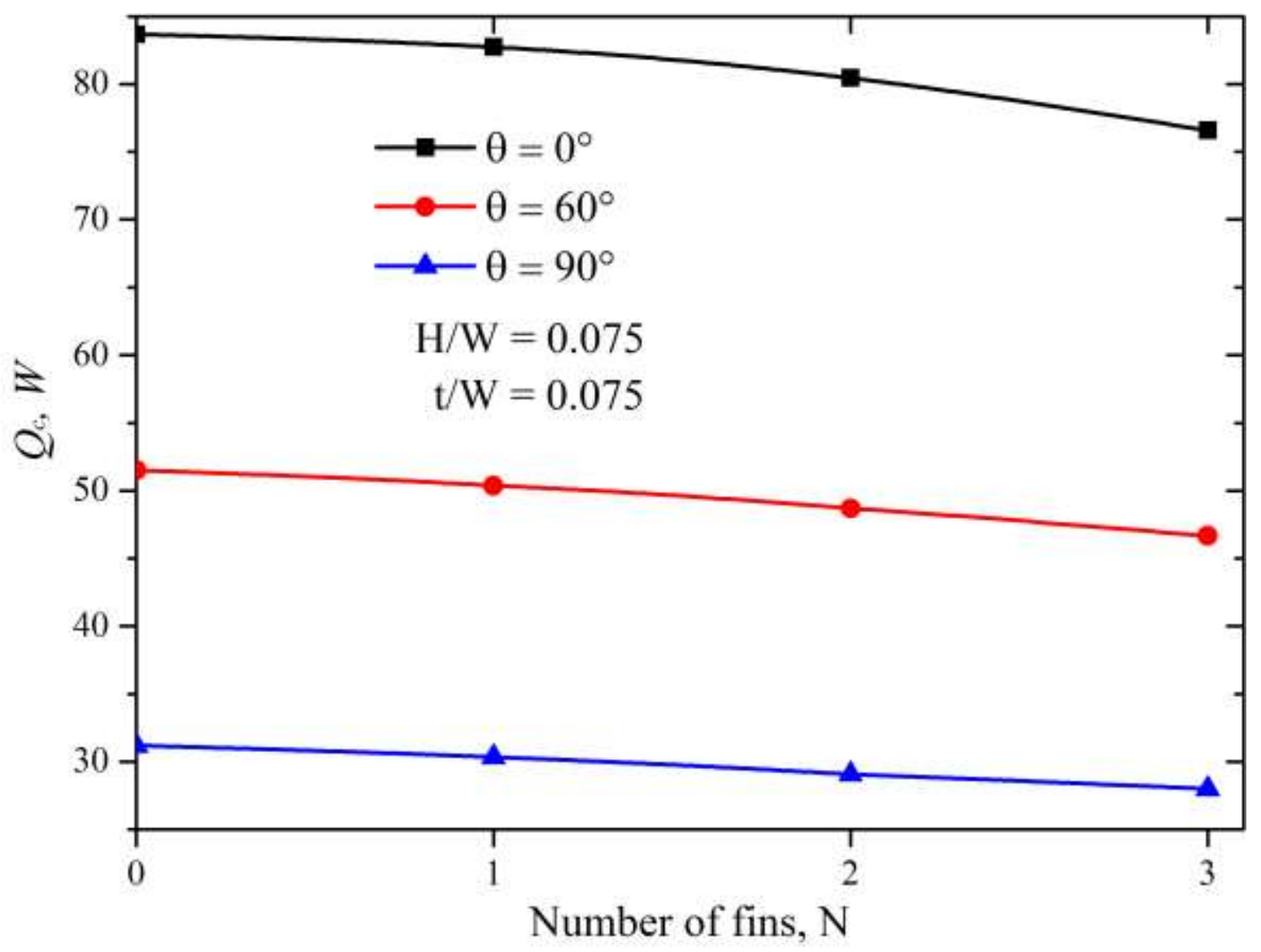

Figure 9. Variation of convection heat loss with number of fins, $R a=10^{6}$ 


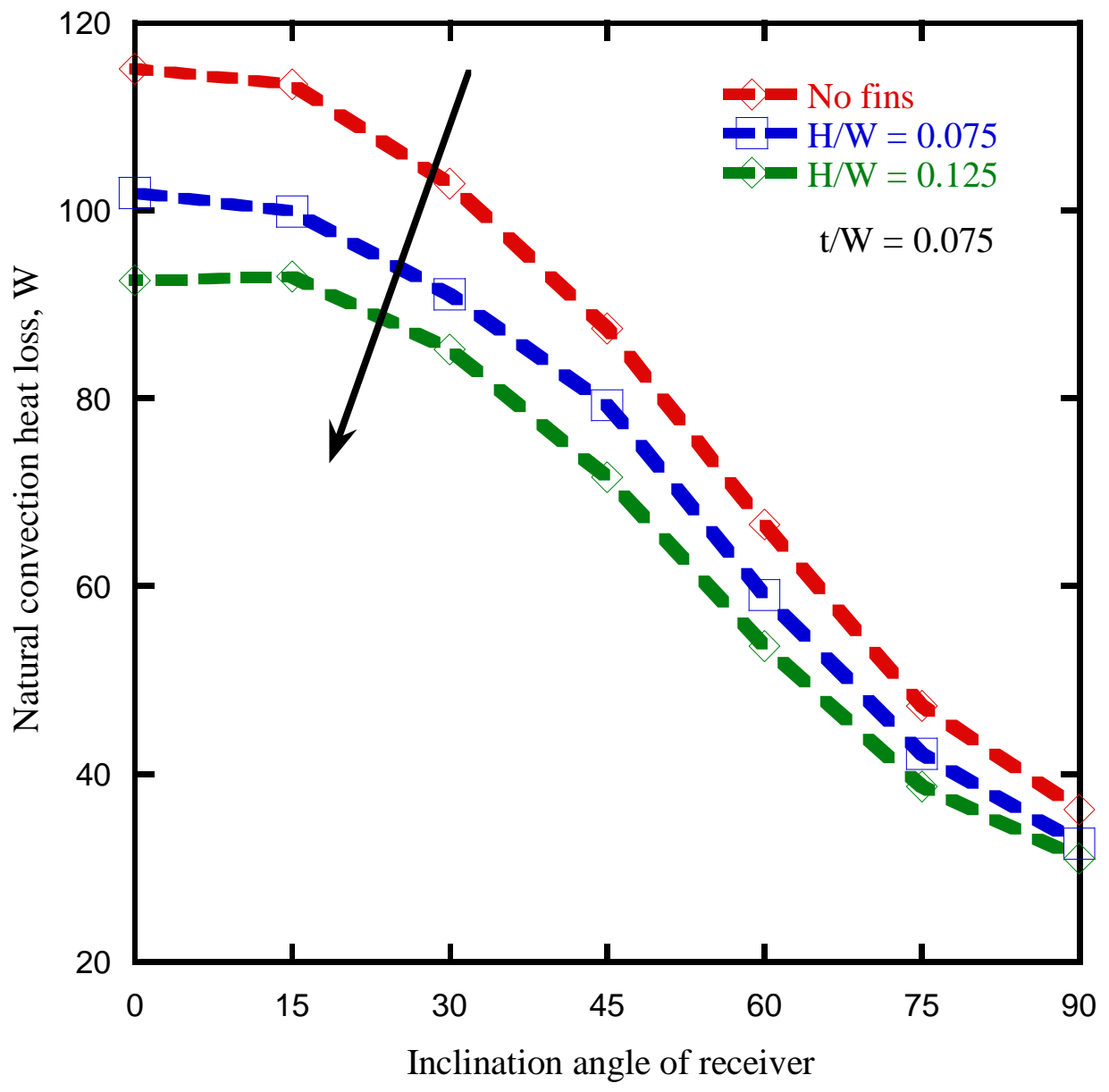

Figure 10. Variation of convection heat loss with receiver inclination angle, $R a=10^{6}$ 


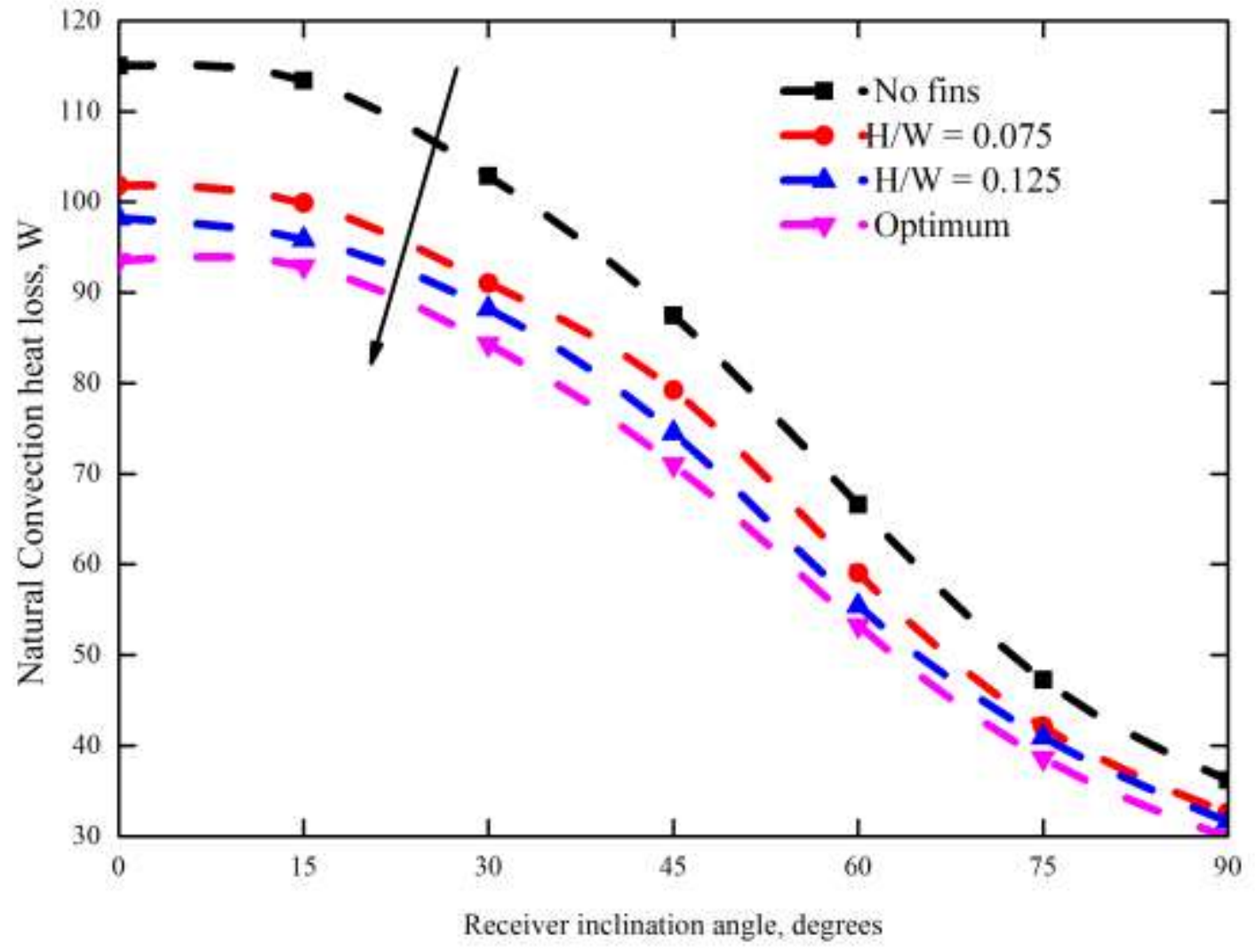

Figure 11. Variation of convection heat loss with receiver inclination angle including optimized results, $R a=10^{6}$ 


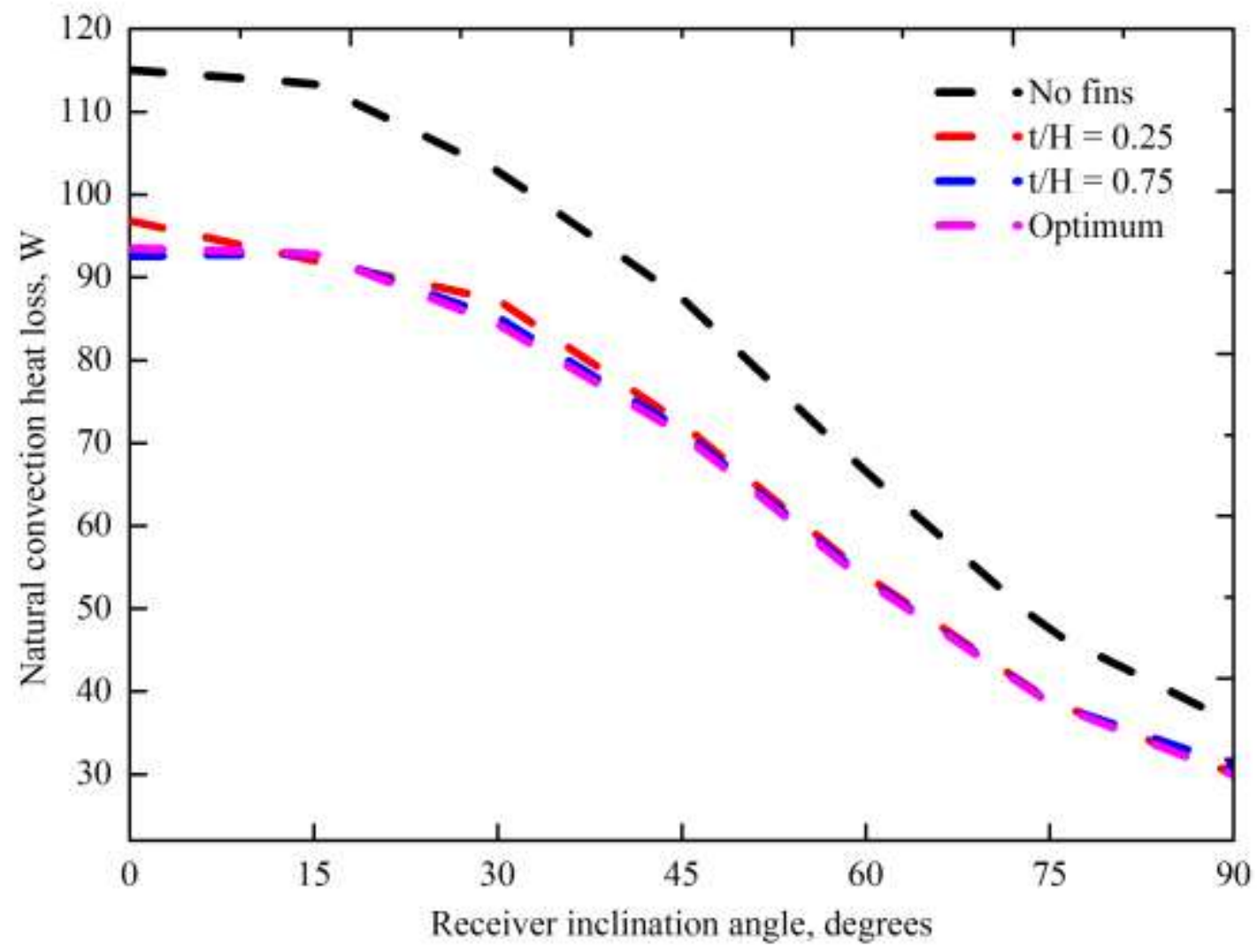

Figure 12. Variation of convection heat loss with receiver inclination angle optimized results, $R a=10^{6}$ 


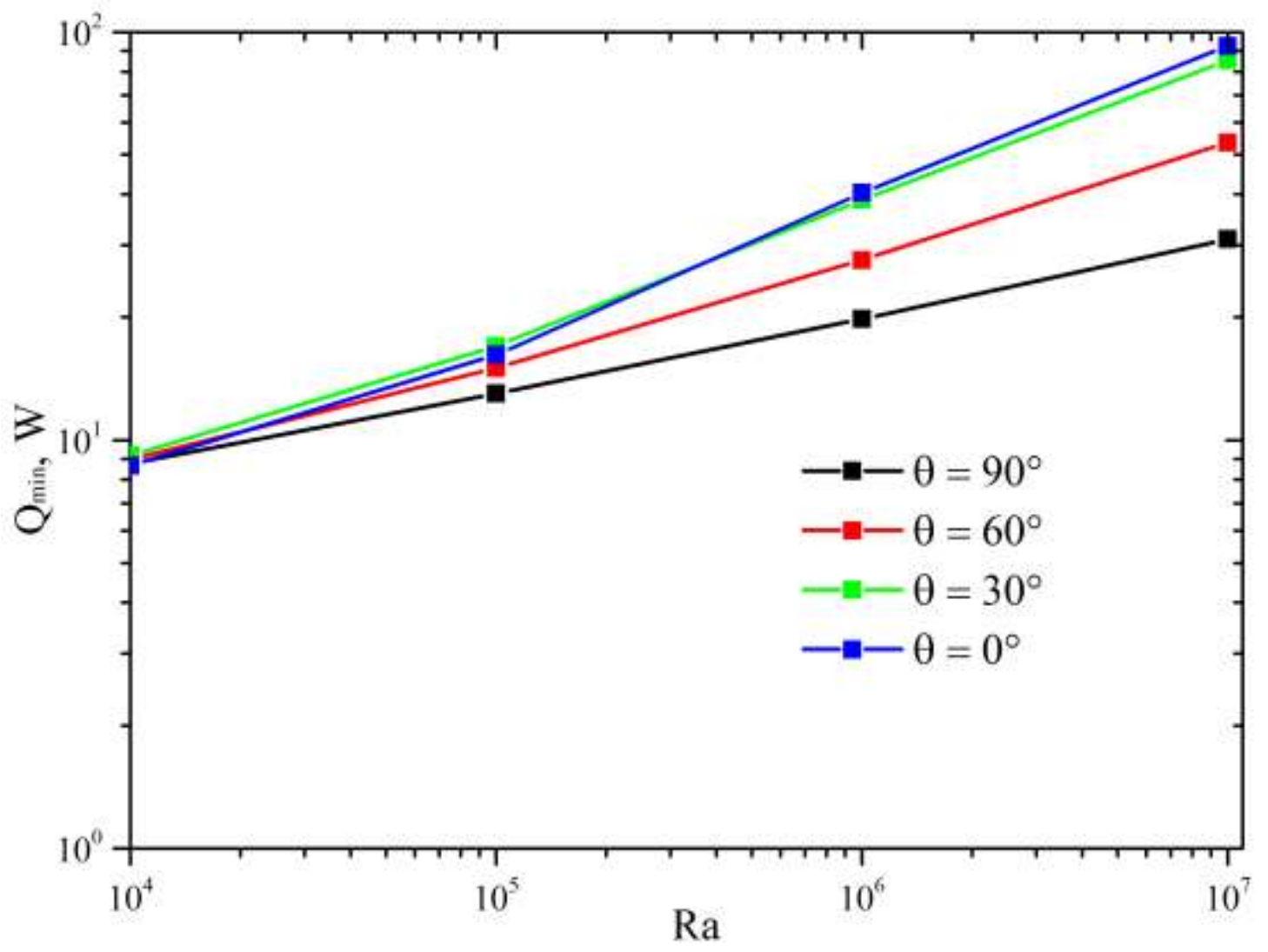

Figure 13. Effect of Raleigh number on minimized natural convection heat loss from the proposed modified cavity. 


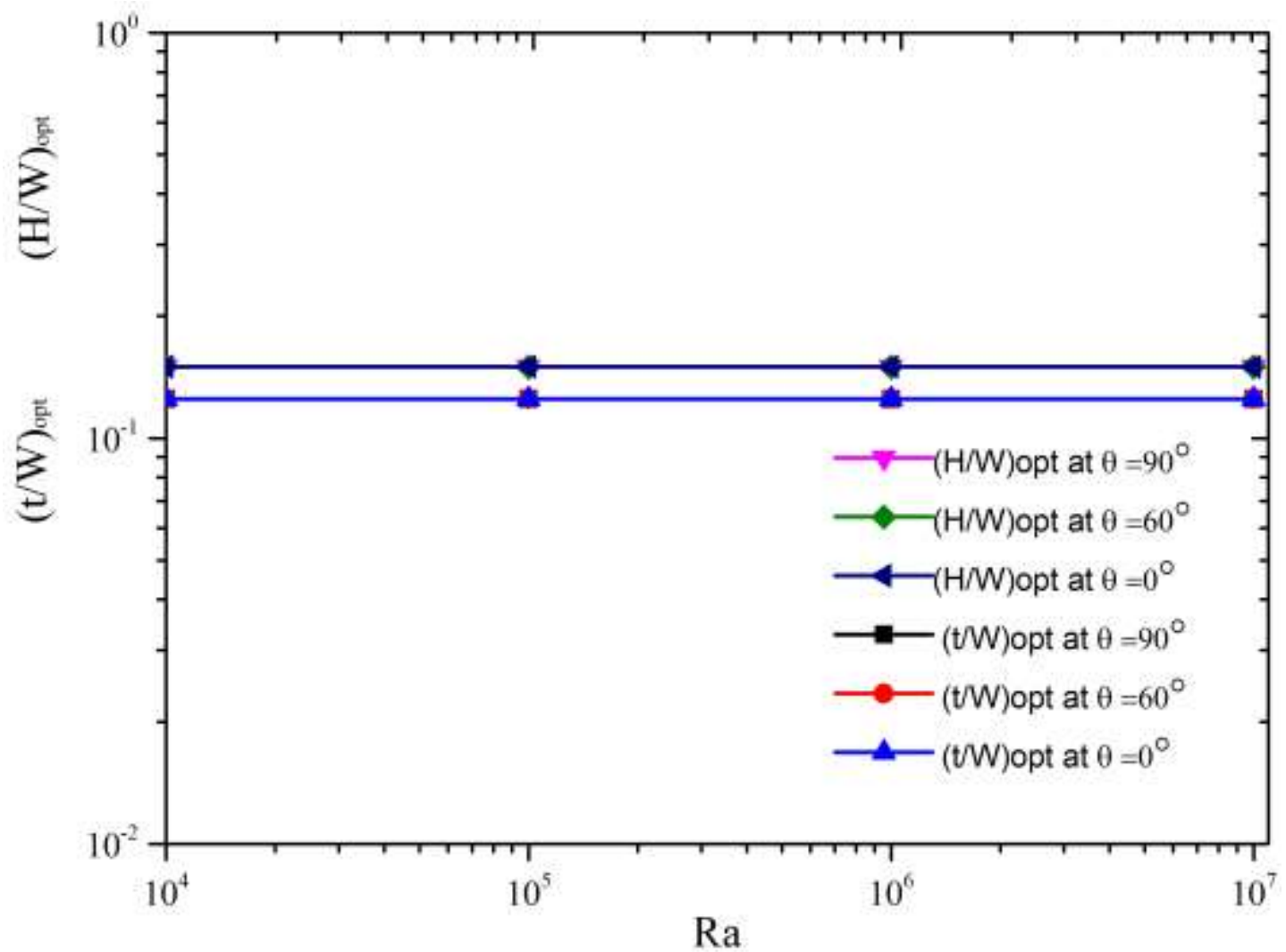

Figure 14. Effect of Raleigh number on optimized dimensionless plate fin heights and thickness. 